\title{
WestVirginiaUniversity
}

THE RESEARCH REPOSITORY @ WVU

Graduate Theses, Dissertations, and Problem Reports

2011

\section{Contributing Factors to Health Anxiety in Older and Young Adults}

\author{
Lindsay Gerolimatos
}

West Virginia University

Follow this and additional works at: https://researchrepository.wvu.edu/etd

\section{Recommended Citation}

Gerolimatos, Lindsay, "Contributing Factors to Health Anxiety in Older and Young Adults" (2011). Graduate Theses, Dissertations, and Problem Reports. 4719.

https://researchrepository.wvu.edu/etd/4719

This Thesis is protected by copyright and/or related rights. It has been brought to you by the The Research Repository @ WVU with permission from the rights-holder(s). You are free to use this Thesis in any way that is permitted by the copyright and related rights legislation that applies to your use. For other uses you must obtain permission from the rights-holder(s) directly, unless additional rights are indicated by a Creative Commons license in the record and/ or on the work itself. This Thesis has been accepted for inclusion in WVU Graduate Theses, Dissertations, and Problem Reports collection by an authorized administrator of The Research Repository @ WVU. For more information, please contact researchrepository@mail.wvu.edu. 
Contributing Factors to Health Anxiety in Older and Young Adults

\author{
Lindsay Gerolimatos, B.S. \\ Thesis submitted to the Eberly College of Arts and Sciences \\ at West Virginia University \\ in partial fulfillment of the requirements \\ for the degree of \\ Master of Science \\ in \\ Psychology
}

Barry Edelstein, Ph.D., Chair

Kevin Larkin, Ph.D.

Aaron Metzger, Ph.D.

Department of Psychology

Morgantown, West Virginia

2011

Keywords: Older Adults; Health Anxiety; Anxiety Sensitivity; Emotion Regulation; Anxiety Control; Intolerance of Uncertainty; Age Differences 


\section{Abstract \\ Contributing Factors to Health Anxiety in Older and Young Adults}

\section{Lindsay A. Gerolimatos}

Researchers have acknowledged overlap in features of health anxiety (HA) and the anxiety disorders. At present, little research on HA exists, especially in its less severe forms, and few studies have examined HA in older adults. Using self-report surveys, the present study examined how anxiety-related constructs contribute to HA in older and young adults and whether these variables differentially account for HA in both age groups. Results showed that young adults reported higher levels of HA than older adults. For both age groups, anxiety sensitivity accounted for illness likelihood and negative consequences, and intolerance of uncertainty contributed to negative consequences. Reappraisal accounted for illness likelihood in older adults, and moderated the relation between anxiety sensitivity and negative consequences in young adults. Anxiety control moderated the relation between anxiety sensitivity and negative consequences in older adults. Overall, results suggest that anxiety sensitivity and intolerance of uncertainty predispose older and young adults to $\mathrm{HA}$, which is influenced by coping strategies. Implications for the conceptualization of HA in both age groups are discussed. 


\section{Acknowledgments}

I would like to thank my advisor and committee chairperson Barry Edelstein for guidance in the design and completion of this study, as well as feedback on drafts of this manuscript.

Thank you, as well, to Kevin Larkin and Aaron Metzger for comments and suggestions as thesis committee members. I would like to thank Christine Gould for her comments on earlier drafts of the manuscript. Finally, I would like to thank my parents, Anthony and Barbara Gerolimatos, as well as Jack and Brenda Molloy and Dan and Florence Molloy for their assistance in recruiting a geographically diverse sample of older adults. 
Table of Contents

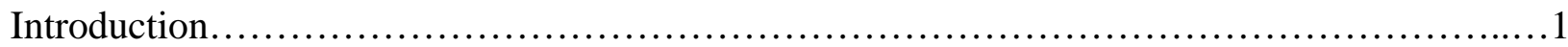

Cognitive-Behavioral Model of Health Anxiety......................................

Similarity to Other Anxiety Disorders............................................ 5

Associated Factors of Health Anxiety............................................8

Pilot Study...............................................................

Age Differences in Anxiety.....................................................16

Statement of the Problem.................................................................

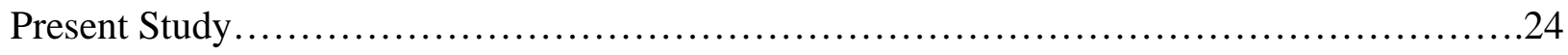

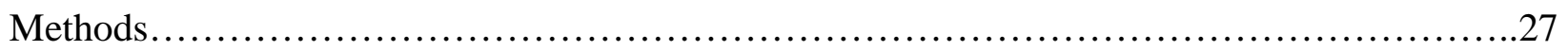

Participants................................................................. 27

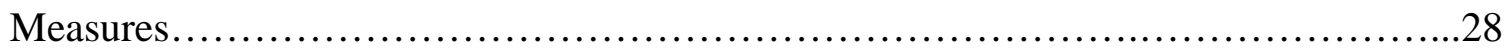

Procedure................................................................

Results............................................................................

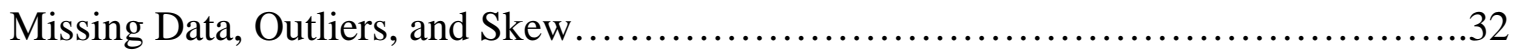

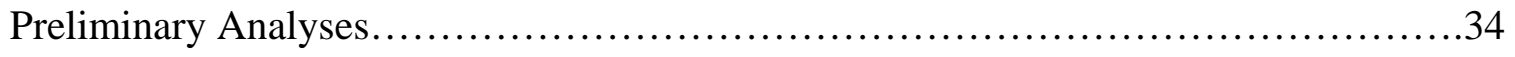

Hierarchical Regression Analyses..........................................35

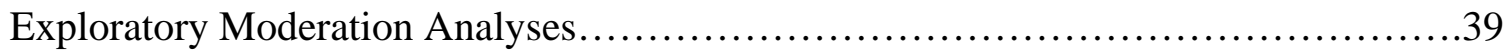

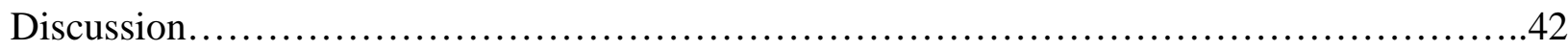

Overview of Findings...................................................43

Age Differences..............................................................44

Anxiety-Related Constructs..............................................46

Implications for the Cognitive-Behavioral Model................................54

Implications for Conceptualization, Assessment, and Treatment....................56

Limitations...................................................................

Future Directions......................................................57

References....................................................................... 59

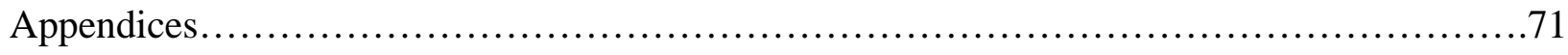

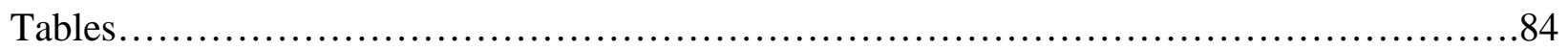

Figures.................................................................... 91

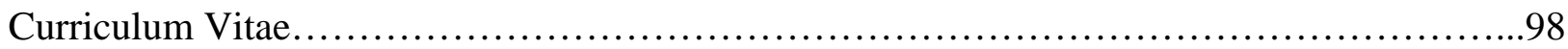




\section{Contributing Factors to Health Anxiety in Older and Young Adults}

According to the Diagnostic and Statistical Manual of Mental Disorders, Fourth Edition, Text Revision (DSM-IV-TR; American Psychiatric Association, 2000), hypochondriasis is characterized by the preoccupation with the fear that one has, or may contract, an illness or serious health problem. In addition, these fears arise from the misinterpretation of bodily symptoms and persist despite reassurance to the contrary, such as a physician's examination. Furthermore, safety behaviors, including checking for bodily symptoms and seeking information on symptoms, typify the patient with hypochondriasis.

Although symptoms of hypochondriasis have been documented throughout history, the disorder was first classified as such in the DSM-II (APA, 1968). However, it was not until the DSM-III (APA, 1980) that the overarching category of Somatoform Disorders was used to describe the cluster of disorders displaying physical symptoms, yet lacking a known physical origin (Noyes, Stuart, \& Watson, 2008). Currently, Somatization Disorder, Conversion Disorder, and Pain Disorder are included in this category, along with hypochondriasis. Recently, this taxonomic system has come under criticism (Noyes et al., 2008) with some researchers arguing that hypochondriasis should instead be classified as one of the Anxiety Disorders (Deacon \& Abramowitz, 2008; Longley, Calamari, Wu, \& Wade, 2010; Noyes et al., 2008). Often, researchers cite that hypochondriasis does not actually manifest itself with physical symptoms and instead is characterized by anxiety, or fear, related to illness (Noyes et al., 2008). Researchers have conceptualized hypochondriasis as the extreme form of health anxiety (Salkovskis \& Warwick, 1986; Taylor \& Asmundson, 2004). That is, health anxiety is a dimensional construct, with individuals exhibiting varying degrees of anxiety, or concern, regarding their health (e.g., Longley, Broman-Fulks, Calamari, Noyes, Wade, \& Orlando, 2010; 
Taylor \& Asmundson, 2004). Indeed, everyone has some level of health anxiety, but few people meet the diagnostic criteria for hypochondriasis ( $1 \%$ to $5 \%$ prevalence rates according to the DSM-IV-TR; APA, 2000). Individuals with health anxiety burden the healthcare system with frequent, unnecessary checkups (Fink, Ørnbøl, \& Christensen, 2010) and are more likely to suffer from anxiety, depression, and physical limitations (Noyes, Happel, \& Yagla, 1999). Currently, there is little research devoted to the study of health anxiety, especially in its more mild forms. Therefore, it is important to understand the factors that contribute to health anxiety. The proposed study examined health anxiety in a sample of college students and older adults. In particular, the current study identified variables that contribute to the severity of health anxiety and assessed the extent to which these variables differentially account for health anxiety in older and younger adults. It is noteworthy that the vast majority of health anxiety research has failed to examine health anxiety in older adults, which is remarkable given that older adults encounter health problems more frequently than younger individuals. Accordingly, older adults may have more anxiety about their health. Although research has examined the role of anxiety sensitivity (fear of anxiety symptoms; e.g., Olatunji, Wolitzky-Taylor, Elwood, Connolly, Gonzales, \& Armstrong, 2009) and intolerance of uncertainty (tendency to react negatively in unpredictable situations; e.g., Deacon \& Abramowitz, 2008) in contributing to health anxiety symptoms in young adults, the present study examined the role of these variables, plus emotion regulation and anxiety control (perceived ability to manage anxiety), in accounting for health anxiety in older and young adults. This study expanded upon previous health anxiety research with young adults by focusing on both older adults and younger adults. Answering these questions enhances the understanding of health anxiety and may alter how researchers and clinicians conceptualize the disorder. 


\section{Cognitive-Behavioral Model of Health Anxiety}

Traditional conceptualizations of hypochondriasis and health anxiety have emphasized the psychodynamic perspective (Taylor \& Asmundson, 2004), which suggests that health anxiety is an enduring personality trait. More recently, greater emphasis has been placed on the cognitions and behaviors associated with hypochondriasis, with treatments targeting these areas (Taylor \& Asmundson, 2004). A commonly referenced model to explain health anxiety is the cognitive-behavioral model proposed by Salkovskis and Warwick (1986). According to this model, health anxiety results from past experiences with illness. These experiences influence attention to illness information. For example, an individual may have lost a parent to brain cancer, and as a result, may become hypervigilant to the signs of brain cancer (e.g., headaches). Moreover, the individual may adopt dysfunctional information processing strategies, such as overestimating the severity of a particular symptom. In this example, an individual with health anxiety would interpret a headache, which is a fairly common and often benign sensation, as indicative of brain cancer. These thought patterns persist despite evidence to the contrary (e.g., a scan of the brain disconfirms the presence of a tumor). Notably, the onset of health anxiety as explained by this model focuses almost exclusively on cognitive factors, largely ignoring physiological arousal and behaviors that accompany anxiety.

The maintenance of health anxiety, and the level of distress experienced by an individual, involves the interaction of four factors: (a) the perceived likelihood of the illness, (b) perceived cost (i.e., negative effects) of the illness, (c) perceived ability to cope with the illness, and (d) availability of rescue factors, such as cures for the illness. As described in the model, the presence of (c) and (d) appear to temper one's perception of (c) and (d). Using the brain cancer example, this individual (a) believes brain cancer to be highly likely, because his parent died 
from the disease, (b) views the cost as being extremely high (i.e., will result in death), (c) does not think he will be able to cope with the illness, and (d) knows that a cure is very unlikely. The interaction of these factors makes this individual highly susceptible to health anxiety and greatly distressed at the prospect of having brain cancer. In contrast, another person may view (b), (c), and (d) in the same way as the individual in the above example, but does not think that brain cancer is likely (e.g., it is a rare disease and this individual is very young). Thus, this individual is not likely to experience distress related to health anxiety. Again, this model emphasizes the role of cognitive factors in the maintenance of health anxiety.

Some factors of the model, such as coping strategies, may manifest as behaviors. Individuals high in health anxiety are more likely to engage in safety-seeking behaviors (e.g., Abramowitz \& Moore, 2007), which include body-checking and information-seeking behaviors. That is, these individuals are more likely to look for information or utilize the healthcare system to confirm or disconfirm the presence of an illness. Interestingly, disconfirming information may be interpreted by the health anxious individual as being erroneous (e.g., the test must have yielded a false negative) and individuals are likely to seek a second opinion or additional information (Hadjistavropoulos, Craig, \& Hadjistavropoulos, 1998).

Evidence in support of this theory is growing. A host of studies have examined the role of specific cognitive processes in maintaining health anxiety (e.g., Hadjistavropoulos et al., 1998; Lees, Mogg, \& Bradley, 2005). Studies often show that health anxious individuals negatively interpret ambiguous symptoms or have attentional biases toward health-related information (see Williams, 2004 for a review). For example, Owens and colleagues (2004) presented participants with words that were illness-related, positive emotions, negative emotions, or neutral during a modified Stroop task. They compared individuals with high, medium, and low levels of health 
anxiety. The highly health anxious group showed significantly greater Stroop interference (i.e., longer reaction times) for illness-related words compared to other kinds of words though the medium and low health anxious groups did not exhibit differences in Stroop interference for any of the word types. These results suggest that health anxious individuals are highly focused on health cues and attend less to other cues (in this case, the color of words).

The present study will examine additional anxiety-related cognitive processes that may be related to the onset or maintenance of health anxiety. In particular, I will focus on how anxiety sensitivity and intolerance of uncertainty contribute to the onset of health anxiety (i.e., perceived illness likelihood and negative consequences factors) and how emotion regulation skills and perceived anxiety control maintain health anxiety (i.e., coping factors). First, I will demonstrate that health anxiety is similar to the anxiety disorders, thus warranting the exploration of anxiety-related factors in health anxiety.

\section{Similarity to Other Anxiety Disorders}

Recently, research on hypochondriasis has explored the extent to which the disorder fits conceptually with the anxiety disorders (Abramowitz \& Moore, 2007; Abramowitz, Olatunji, \& Deacon, 2007; Lees et al., 2005). Although the DSM-IV-TR (APA, 2000) currently categorizes health anxiety (i.e., hypochondriasis) as a somatoform disorder, such a classification may reflect convention rather than the current state of the literature (Abramowitz \& Moore, 2007). For example, panic disorder tends to co-occur with hypochondriasis and these two disorders share similar characteristics, such as hypervigilance to body sensations. These similarities suggest a common etiology (Abramowitz, Olatunji, \& Deacon, 2007; Taylor \& Asmundson, 2004). Moreover, current conceptualizations of the disorder, as described above in the cognitivebehavioral model of health anxiety, emphasize cognitive factors in the onset and maintenance of 
health anxiety, as opposed to somatic origins of the disorder (Taylor \& Asmundson, 2004). The role of cognitions is particularly relevant to the anxiety disorders, rather than somatoform disorders (Deacon \& Abramowitz, 2008). Altogether, this information suggests that health anxiety, and hypochondriasis, may fit better conceptually with the anxiety disorders. Classifying health anxiety as an anxiety disorder will have implications for the conceptualization, diagnosis, and treatment of the disorder. The following section will summarize the literature that draws parallels between health anxiety and various anxiety disorders.

Trait anxiety. Trait anxiety is an enduring pattern of anxious responses to various events. Studies have consistently demonstrated associations between measures of trait anxiety and measures of health anxiety (e.g., Bourgault-Fagnou \& Hadjistavropoulos, 2009), such that those who have an anxious predisposition are more likely to also have health anxiety. Similarly, individuals who have been diagnosed with generalized anxiety disorder (GAD) are also likely to score high on a measure of health anxiety (Abramowitz, Olatunji, \& Deacon, 2007), though their scores are not as high as individuals with hypochondriasis. In addition, one of the defining features of GAD is excessive worry. Worry is defined as intrusive thoughts about a future event. Worry in GAD, therefore, is akin to preoccupation in hypochondriasis. That is, individuals who are health anxious have intrusive, excessive thoughts (i.e., worry) and these thoughts often center on the possibility of having an illness in the future. Individuals with trait anxiety also exhibit attentional biases for threat words (Fox \& Knight, 2005; Hazen, Vasey, \& Schmidt, 2009), which has also been shown in health anxiety (e.g., Lees et al., 2005). Thus, it appears that trait anxiety and health anxiety share some common features as well as underlying cognitive processes, suggesting that these two constructs may be closely related.

Panic disorder. Much research has demonstrated similarities between Panic Disorder 
and health anxiety. First, individuals with high levels of health anxiety and individuals with Panic Disorder score higher on the Short Health Anxiety Inventory (SHAI; Salkovskis, Rimes, Warwick, \& Clark, 2002) relative to individuals with other anxiety disorders (Abramowitz, Olatunji, \& Deacon, 2007). When examining the signs and symptoms of hypochondriasis and panic disorder, several similarities emerge. For instance, both disorders center on hypervigilance for bodily sensations. Specifically, individuals with these disorders are particularly sensitive to physical sensations and often interpret sensations as indicative of a serious physical or medical condition (Olatunji et al., 2009). According to a study by Starcevic, Berle, Fenech, Milicevic, Lamplugh, and Hannan (2009), individuals with panic disorder are more likely to hold negative beliefs about the consequences of physical symptoms (e.g., as signifying a dire medical emergency such as heart attack) and are also likely to endorse hypochondriacal beliefs, such as thinking they have a disease despite being told by a physician they do not. To summarize, both panic and health anxiety involve sensitivity to bodily sensations, which trigger fears of impending health woes. Once again, these findings indicate that panic disorder and health anxiety share common symptoms and processes.

Obsessive-compulsive disorder. Recently, a focus of health anxiety research has been to examine similarities between OCD and health anxiety. Particular attention has been placed on shared features of the disorder. For instance, a common presentation of OCD is fear of contamination (APA, 2000), in which one is afraid of coming into contact with germs. Taking this one step further, it is likely that contamination fear might also reflect a fear of contracting an illness. Hence, both health anxiety and OCD are characterized by the fear of becoming ill (e.g., Deacon \& Abramowitz, 2008). Of course, there are many varieties of obsessions in OCD (i.e., not all individuals with OCD fear contamination; Steketee, Grayson, \& Foa, 1985); however, it is 
a common fear among individuals with the disorder. In addition, certain behaviors that characterize OCD and health anxiety are similar. One of the most notable signs of OCD is the compulsive rituals in which individuals engage to reduce anxiety. Recently, these behaviors have been likened to the safety- and reassurance-seeking behaviors of health anxiety (e.g., Abramowitz \& Moore, 2007). In particular, individuals with high levels of health anxiety often engage in safety behaviors, such as consulting with physicians, seeking illness information from various sources (e.g., friends, the internet), and checking the body for symptoms (Taylor \& Asmundson, 2004). Abramowitz and Moore (2007) demonstrated that safety behaviors are similar to compulsions in OCD in that they reduce anxiety about having an illness. In their study, highly health anxious participants were exposed to personally relevant health anxiety triggers (e.g., reading a story about someone who died from a disease). One group of participants was allowed to engage in safety behaviors following exposure (the safety behavior group), while the other group was not (the response prevention group). Subjective ratings of anxiety were significantly different between the groups, such that the response prevention group reported higher levels of anxiety. These results show that safety seeking behaviors do reduce anxiety (albeit only temporary) and suggest that health anxiety follows the same patterns as obsessivecompulsive disorder. In fact, it has been proposed that health anxiety be grouped under the Obsessive-Compulsive Spectrum Disorders in the DSM-V (Asmundson, 2010). Current research continues to examine the similarities between these two disorders.

\section{Associated Factors of Health Anxiety}

Numerous factors have been examined in relation to health anxiety. Although some variables (e.g., anxiety) have been extensively studied, others, such as intolerance of uncertainty, require further examination. Still others (e.g., emotion regulation, anxiety control) have not been 
examined in relation to health anxiety, but have been studied in relation to other anxiety disorders (see Starcevic \& Berle, 2006 for a review). Given the similarities between health anxiety and the anxiety disorders, these variables should also relate to health anxiety. Demonstrating that health anxiety shares similar factors with other anxiety disorders will provide support for the reconceptualization of health anxiety as an anxiety disorder. The following section summarizes the research on various constructs related to health anxiety.

Anxiety sensitivity. Anxiety sensitivity is a cognitive preoccupation regarding fear of anxiety-related symptoms, such as increased heart rate, breathing, and sweating. It is considered a unique predictor of the anxiety disorders, most notably panic (Deer \& Calamari, 1998; Reiss \& McNally, 1985), but also GAD and PTSD (see Naragon-Gainey, 2010 for a meta-analysis). A number of studies have demonstrated that scores on measures of anxiety sensitivity are related to measures of health anxiety (e.g., Olatunji et al., 2009), such that highly health anxious individuals also score high on a measure of anxiety sensitivity. This trend has been demonstrated in non-clinical college samples (Sexton, Norton, Walker, \& Norton, 2003) and outpatient clinical samples (Norton, Sexton, Walker, \& Norton, 2005). The relation between health anxiety and anxiety sensitivity has also been explored in older adults, though only one study presently exists. Bravo and Silverman (2001) found that older adults referred to a clinic for depression had higher levels of anxiety sensitivity and greater hypochondriacal symptoms than non-referred older adults. Also, anxiety sensitivity was a better predictor of health anxiety symptoms than either depression or anxiety (Bravo \& Silverman). Overall, anxiety sensitivity appears to contribute to health anxiety in a variety of populations.

In addition, studies have illustrated that anxiety sensitivity is associated with particular symptoms of health anxiety. For example, Lees et al. (2005) demonstrated that individuals with 
high levels of anxiety sensitivity had greater attentional biases for words and images denoting health threat. This finding is particularly noteworthy given that one of the components of hypochondriasis is a cognitive bias for health-related information, with particular focus on negative health information. It has also been shown that anxiety sensitivity, in particular sensitivity to physical concerns, predicts body vigilance in a nonclinical sample, whereas sensitivity to mental health concerns predicts emotional avoidance as a regulation strategy (Zvolensky \& Forsyth, 2002). However, more research on the role anxiety sensitivity plays in health anxiety is needed. Although it is well established that anxiety sensitivity and health anxiety are related, it is unknown as to how anxiety sensitivity may interact with or mediate other variables to account for health anxiety. Also, it is important to determine how anxiety sensitivity contributes to health anxiety across the lifespan.

Intolerance of uncertainty. Recently, many researchers have examined the role of intolerance of uncertainty in accounting for the presence and severity of health anxiety (e.g., Deacon \& Abramowitz, 2008). Individuals who are intolerant of uncertainty generally react with anxious arousal in situations for which one cannot control or plan. Most often, this feature has been examined in relation to GAD; those who score higher on a measure of intolerance of uncertainty are much more likely to endorse excessive worry (Sexton et al., 2003) or have a diagnosis of GAD (Norton et al., 2005). Further, intolerance of uncertainty mediates the relation between neuroticism and worry (de Bruin, Rassin, \& Muris, 2007; Sexton et al., 2003). Though little research on intolerance of uncertainty in older adults exists, one study examining worry showed that older adults report less intolerance of uncertainty than younger adults (Basevitz, Pushkar, Chaikelson, Conway, \& Dalton, 2008). Another study on aging and older adults (Nuevo, Wetherell, Montorio, Ruiz, \& Cabrera, 2009) demonstrated that intolerance of 
uncertainty partially mediated the relation between knowledge about aging and worry associated with aging.

As one can imagine, individuals with health anxiety are intolerant of uncertainty; when experiencing a vague body sensation, they feel compelled to engage in safety behaviors to determine whether they have an illness. Even when they learn new information disputing the existence of an illness, they are not relieved; they are not certain that that diagnostic test was accurate, and consequently, anxiety continues (Starcevic \& Berle, 2006). In fact, some research suggests that intolerance of uncertainty may relate to specific health behaviors, such as body checking and monitoring (Rosen, Knäuper, \& Sammut, 2007). However, other studies have been unable to find a link between intolerance of uncertainty and safety behaviors (e.g., Fergus \& Valentiner, 2009). Deacon and Abramowitz (2008) demonstrated that individuals with extreme health anxiety (i.e., a diagnosis of hypochondriasis) had significantly elevated scores on the Intolerance of Uncertainty Scale (IUS; Freeston, Rhéaume, Letarte, Dugas, \& Ladocuer, 1994) relative to individuals with panic disorder. Scores on the IUS in the health anxious sample were comparable to IUS scores for individuals with a principal diagnosis of OCD. In addition, Carleton, Sharpe, and Asmundson (2007) found that intolerance of uncertainty was related to a variety of anxiety-related constructs, such as illness fear. They argue that fear of illness alone is not enough to develop health anxiety and intolerance of uncertainty is a necessary component. Conversely, Norton et al. (2005) and Sexton et al. (2003) failed to find a relation between health anxiety and intolerance of uncertainty in clinical and non-clinical samples, respectively. Notably, research on the relation between intolerance of uncertainty and health anxiety is fairly new and has not been examined in older adults. Hence, additional support is needed.

Emotion and affect regulation. Emotion regulation, which is comprised of several 
strategies, has recently been examined in relation to several anxiety disorders. For example, Mennin, McLaughlin, and Flanagan (2009) have shown that individuals with GAD and social anxiety disorder (SAD) have emotion regulation deficits. In particular, poor emotional understanding predicted SAD while intense display of emotions was a better predictor of GAD. Individuals with co-morbid SAD and GAD also exhibited greater non-acceptance of emotions (Decker, Turk, Hess, \& Murray, 2008). Similarly, Gould and Edelstein (2010) found that emotion control was related to less worry, once again suggesting that individuals with symptoms of GAD tend to have greater difficulty with emotional control.

In addition, emotion regulation in Panic Disorder has recently been explored. Tull and Roemer (2007) reported that individuals with a history of panic attacks are significantly more likely to have difficulties in emotion regulation relative to individuals without panic. Similar to Decker et al. (2008), individuals with panic also displayed more negative emotions in response to film clips (Tull \& Roemer, 2007). Moreover, these individuals were also more likely to engage in emotional avoidance of the film clips. In an examination of individuals with a history of uncued panic attacks, Tull, Rodman, and Roemer (2008) demonstrated that fear of bodily sensations predicted emotion regulation difficulties, including experiential avoidance, emotional non-acceptance, and lack of emotional clarity. Given that fear of body sensations also characterizes health anxious individuals, it is likely that these individuals will display similar emotion regulation difficulties. Finally, Tull, Stipelman, Salters-Pedneault, and Gratz (2009) provide preliminary evidence that associations between GAD and panic disorder may in fact be explained by shared variance with emotion regulation difficulties. Overall, it appears that emotion regulation may be related to health anxiety.

Additional evidence of the link between emotion regulation and anxiety comes from 
research on aging. Older adults are particularly skilled at regulating emotions, and consequently, experience less distress compared to younger adults (e.g., Charles \& Carstensen, 2007). Specifically, older adults tend to focus more on positive emotions, with a decrease in the experience of negative emotions, a phenomenon known as the positivity bias (Mather \& Carstensen, 2005). Similarly, older adult are more skilled at engaging in emotion-regulatory problem-solving — as opposed to problem-focused coping — relative to younger adults (Blanchard-Fields, Stein, \& Watson, 2004). On a related note, research suggests that older adults are more likely than younger adults to use more passive emotion-coping strategies, such as avoidance of negative stimuli (e.g., Blanchard-Fields \& Coats, 2008). Collectively, these regulatory skills may partially explain why older adults are less susceptible to psychological distress (Gross \& John, 2003). Age differences in anxiety and explanations for these differences will be explored later in this manuscript. However, it appears that emotion regulation plays a key role in accounting for various anxiety disorders, and theoretically, should relate to health anxiety.

To date, only one study to our knowledge examined the role of emotions in health anxiety. Researchers found that high emotional preoccupation (i.e., focusing on the emotional consequences of one's health) was a predictor of health anxiety in a sample of community dwelling older adults (Bourgault-Fagnou \& Hadjistavropoulos, 2009). These researchers also demonstrated that emotional preoccupation mediated the relation between frailty and scores on a measure of health anxiety. Additionally, one study has examined emotion and affect regulation in the somatoform disorders (Waller \& Scheidt, 2004). These researchers found that individuals diagnosed with a somatoform disorder scored lower on measures of affect regulation compared to healthy controls. Interestingly, this study found no differences in emotional awareness (i.e., recognition of emotions in self and others) between the groups. Although they did not examine 
emotion regulation in health anxiety per se, these results provide support for the notion that health anxious individuals may lack the ability to self-regulate. Similarly, there has been some research examining coping strategies in health anxiety. For example, Hadjistavropoulos and colleagues (1998) found that undergraduate students with health anxiety were more likely to use avoidance as a coping strategy; these individuals also had difficulty in monitoring their sensations. Thus, one might infer that health anxious individuals are less skilled at self-control, which may suggest poor emotion regulation as well. Because emotion regulation has consistently been shown to relate to the anxiety disorders, it is worthwhile to examine the role of emotion regulation in health anxiety.

Anxiety control. Anxiety control refers to the extent to which one believes that one has control over a situation and subsequent internal and external experiences of, or reactions to, the situation. Anxiety control has not been examined in relation to health anxiety but has been explored in a variety of other anxiety constructs. Gould and Edelstein (2010) demonstrated a relation between anxiety control and worry in older and younger adults, such that greater control was associated with less reported worry. Remarkably, older and younger adults did not differ in anxiety control (Gould \& Edelstein). In a study of socially anxious adults aged 18 to 74 years, perceived control of anxiety symptoms mediated the relation between the estimated cost of a social interaction (i.e., that a negative interaction will have catastrophic outcomes) and the experience of anxiety (Hofmann, 2005). In other words, individuals who felt more in control of their anxiety were less likely to experience anxious distress. Anxiety control significantly predicts both anxiety and depressive symptoms in children and adolescents (Weems, Costa, Watts, Taylor, \& Cannon, 2007). Similarly, in a sample of children and adolescents, anxiety control partially mediated the relation between anxiety sensitivity and anxiety symptoms (Marin, 
Rey, Nichols-Lopez, \& Silverman, 2008). The majority of these studies did not directly study anxiety control in older adults; however, it is likely that older adults will be more skilled at controlling anxiety given that older adults also tend to display greater skill at regulating emotions (Gross \& John, 2003). Although few studies have examined anxiety control, there exists some evidence supporting the notion that anxiety control mediates the experience of anxiety.

\section{Pilot Study}

To better understand the relations among anxiety-related constructs in accounting for health anxiety, a number of the variables described above were examined in a pilot study on undergraduate college students (Gerolimatos \& Edelstein, in preparation). This study examined anxiety sensitivity, general anxiety, and worry in accounting for health anxiety, with emotion regulation examined as a coping factor. Hierarchical regression analyses were conducted with health anxiety scores as the criterion variable and physical and mental health scores included as statistical controls. Results of the hierarchical regression analyses showed that only anxiety sensitivity and general anxiety directly related to health anxiety. Mediation analyses revealed anxiety sensitivity as a mediator of the relation between worry and health anxiety, suggesting that perhaps worries about physical sensations contributes to health anxiety through its relation to anxiety sensitivity. Finally, the emotional regulation strategy of reappraisal moderated the relation between anxiety sensitivity and the illness likelihood, which describes one's certainty that one may have an illness. This finding indicates that the relation between anxiety sensitivity and illness likelihood is dependent upon the use of reappraisal. Likewise, the emotion regulation strategy of suppression moderated the relation between general anxiety and the negative consequences, which assesses negative effects of an illness.

The results of the pilot study relate to the present study in several ways. First, these 
results provided additional support for anxiety sensitivity as a key contributor to health anxiety. Second, results indicated that general anxiety is also strongly related to health anxiety. Therefore, other variables associated with general anxiety (e.g., intolerance of uncertainly, perceived anxiety control) may also relate to health anxiety. Third, two emotion regulation strategies were identified as moderators of the relations between anxiety-related constructs and health anxiety. Consequently, it appears that emotion regulation may also be an important contributor to health anxiety. In particular, reappraisal and suppression may act as moderators of anxiety-related factors and health anxiety, not as a mediator like other research suggests (e.g., Bourgault-Fagnou \& Hadjistavropoulos, 2009). Collectively, these results suggest that anxiety sensitivity, intolerance of uncertainty, emotion regulation, and perceived anxiety control may relate to health anxiety and should be explored further.

\section{Age Differences in Anxiety}

Few studies have examined health anxiety in older adults, and even fewer have compared health anxiety in older and younger samples. To our knowledge, only two studies have examined health anxiety in older adults. Boston and Merrick (2010) found that older adults in New Zealand are equally health anxious compared to younger individuals. However, they did not directly compare young and elderly samples; rather, they gathered data on older adults and then compared these results to the literature on health anxiety in young adults. These researchers also examined several demographic factors and demonstrated that lower education and decreased physical functioning significantly contribute to scores on a measure of health anxiety. In another study, Bourgault-Fagnou and Hadjistavropoulos (2009) examined the moderating role of frailty in explaining health anxiety. Frailty is defined as vulnerability for illness or physical limitations, which can be indicated by cognitive and physical health, number of medications, level of 
independence, and social support. They found that high-frailty older adults (i.e., those most vulnerable to morbidity) had the highest levels of health anxiety compared to low-frailty older adults and college students. However, when controlling for health issues, the high-frailty older adults scored similarly to the college sample on a measure of health anxiety. Low-frailty older adults had the lowest levels of health anxiety among the three groups. Given that only two studies on health anxiety in older adults have been published in recent years, more research on this population is needed.

In light of the paucity of literature on age differences in health anxiety, the next section will address age differences in the prevalence rates and features of other forms of anxiety, but with a focus on health. Anxiety disorders are the most common psychological disorder among adults over the age of 55 (American Association for Geriatric Psychiatry, 2004), with estimates of anxiety prevalence in community-dwelling older adults ranging from $1.2 \%$ to $15 \%$ (Bryant, Jackson, \& Ames, 2008). In younger adult samples, prevalence rates are higher (WolitzkyTaylor, Castriotta, Lenze, Stanley, \& Craske, 2010), suggesting that anxiety decreases across the lifespan. Worry, the main feature of GAD, tends to decrease across the lifespan (Basevitz et al., 2008), with older adults reporting less worry (Brenes, 2006). Interestingly, the content of worries also changes across the lifespan. For example, older adults are more likely than young adults to report concern over family issues and health, but both older and younger adults are equally likely to report worrying over finances and social situations (Hunt, Wisocki, \& Yanko, 2003). Overall, it has been consistently demonstrated that health is the most frequently reported worry among older adults (e.g., Wisocki, 1994).

Similarly, the two most commonly endorsed fears among older adults include cognitive decline and having an illness (Kogan \& Edelstein, 2004), whereas younger adults tend to cite 
more social situations as fear-eliciting (Chapman, Kertz, Zurlage, \& Woodruff-Borden, 2008). This trend has also been demonstrated experimentally (Teachman \& Gordon, 2009). Older and younger adults were asked to perform a series of tasks, two of which were physically threatening (e.g., candle-blowing and straw breathing tasks resulting in dizziness and shortness of breath), and one of which was socially threatening (giving a speech). Older adults experienced greater distress when faced with a physical threat compared to a social threat, whereas younger adults were equally likely to experience distress as a result of both the physical and social threats (Teachman \& Gordon, 2009). Generally, these results indicate that older adults are likely to experience anxiety when the trigger (i.e., stimulus) for anxiety is particularly salient to older adults. For instance, because older adults are more likely to suffer from physical illness, they are therefore more likely to experience anxiety in reaction to physical threat or illness. Younger adults, however, tend to respond anxiously to a wider range of stimuli. Despite these age differences in health and concern over one's own physical well-being, the limited research on health anxiety suggests that overall, older adults and young adults experience health anxiety approximately equally (Barsky, Frank, Cleary, Wyshak, \& Klerman, 1991).

In addition to age differences in the content of fear and worry, as well as differences in responses to age-relevant anxiety-inducing stimuli, older and younger adults also tend to display different symptom presentations. In an examination of GAD, researchers found that older adults tend to endorse fewer somatic symptoms (e.g., muscle tension, nausea) and cognitive symptoms (e.g., negative self-evaluation) of anxiety relative to younger and middle aged adults (Brenes, Knudson, McCall, Williamson, Miller, \& Stanley, 2008). Further, older adults tend to report less negative affect but greater positive affect relative to other age groups (Brenes, et al., 2008). Older adults also tend to describe the experience of anxiety in terms of somatic symptoms 
(Palmer, Jeste, \& Sheikh, 1997), whereas younger adults are likely to also describe affective and cognitive symptoms. Interestingly, older adults are also poorer at identifying the somatic, affective, and cognitive features of anxiety and depression relative to younger adults (Wetherell et al., 2009). Therefore, older adults may not necessarily experience fewer or different symptoms of anxiety, rather, they simply misattribute these symptoms (e.g., shortness of breath is due to a physical illness rather than anxiety).

Age differences in prevalence rates of the anxiety disorders and health anxiety in particular may be explained by many developmental changes that occur across the lifespan. As described earlier, older adulthood is marked by a tendency to attend to and remember positive stimuli, while downplaying negative influences (Mather \& Carstensen, 2005). This trend is known as the positivity bias. Conversely, younger adults are more likely to attend to and recall negative information (Charles, Mather, \& Carstensen, 2003). According to Socioemotional Selectivity Theory (Carstensen, 1991), as older adults have an increasingly limited future-time perspective (i.e., as they near the end of their life), they become more motivated to maintain positive relationships with other individuals and minimize negative aspects of social interactions. Younger adults, on the other hand, have an open-ended future time perspective, and are inclined to engage in information seeking. By selectively attending to positive stimuli or engaging in positive interactions, older adults are more likely to experience positive emotions as a result. In terms of anxiety disorders, it may be the case that older adults attend to stimuli that are nondistressing, which may explain their lower levels of anxiety relative to younger populations.

Lastly, age differences in anxiety may be the result of physical and physiological changes that occur in late life. A recent meta-analysis of physiological reactivity in older adults showed that in various laboratory tasks, older adults exhibited less heart rate reactivity than young adults 
(Uchino, Birmingham, \& Berg, 2010). The authors suggested that the reduction in heart rate reactivity may be the result of decreased functioning of myocardial $\beta$-adrenergic receptors that occurs with age (Bertel, Bühler, Kiowski, \& Lütold, 1980). As a result, older adults tend to display attenuated heart rate (Gitner, Hollandsworth, \& Intrieri, 1986) relative to younger adults, and there is less variability in heart rate (Stein, Kleiger, \& Rottman, 1997). Another measure of physiological arousal is blood pressure; older adults tend to have higher blood pressure overall (Lakatta, 1993). Studies examining systolic and diastolic blood pressure as a measure of anxious arousal found that increased age is related to greater blood pressure reactivity to psychological stress (Jennings, Karmarck, Manuck, Everson, Kaplan, \& Salonen, 1997). Furthermore, older adults may have longer recovery times following autonomic arousal (Garwood, Engel, \& Capriotti, 1982). Some researchers have suggested that the measurement of blood pressure is a more sensitive method than heart rate measurement for assessing physiological arousal in older adults (Uchino et al., 2010). One last measure of autonomic arousal is skin conductance, in which older adults show decreased skin conductance which may be due to decreased concentration of sweat glands with aging (Shmavonian, Miller, \& Cohen, 1968). Therefore, depending on which physiological function one measures (e.g., heart rate or skin conductance), older adults may seem less physiologically aroused when anxious compared to other age groups as a result of age-related physical changes. As anxiety disorders are characterized by physiological arousal, some symptoms of anxiety may go unnoticed in the older client. Because age differences have been established in a variety of disorders (e.g., GAD, SAD, etc.), it is necessary to understand whether there are age differences in health anxiety as well. What's more, it is important to understand how age differences in anxiety control, emotion regulation, and other variables may affect the experience of health anxiety. Although 
physiological differences in health anxiety are beyond the scope of this paper, it remains a question of clinical importance. Given that older adults are more likely to suffer from a physical ailment, it is especially prudent to examine age differences in health anxiety.

\section{Statement of the Problem}

Hypochondriasis is marked by the preoccupation with the fear that one has, or may contract, an illness (APA, 2000). Currently, hypochondriasis falls within the category of somatoform disorders, a cluster of disorders in which the symptoms mimic physical ailments though lack a physical cause (APA, 2000). With the development of the cognitive-behavioral model of health anxiety (Salkovskis \& Warwick, 1986), some researchers have conceptualized hypochondriasis as the extreme form of health anxiety, placing greater emphasis on cognitive factors associated with the disorder, rather than on physical or somatic complaints (Salkovskis \& Warwick, 1986; Taylor \& Asmundson, 2004). Because individuals with high levels of health anxiety are concerned they may have an illness, they are more likely to burden the healthcare system with frequent check-ups from their physician or diagnostic tests (Fink et al., 2010). Further, the health anxious individual is more likely to suffer from anxiety and depression, as well as experience greater physical limitations, poorer work performance, and increased incidences of disability (Noyes et al., 1999). Consequently, health anxiety can have significant deleterious effects on an individual's well-being and functioning.

Though the diagnosis of hypochondriasis has existed since the publication of the DSM-II (APA, 1968), little is known about features of the disorder, especially in its less severe presentation as health anxiety. Recently, many researchers have looked to factors associated with the anxiety disorders to account for the experience of health anxiety and its symptoms. In particular, a great deal of research has focused on the role of anxiety sensitivity and intolerance 
of uncertainty in explaining the experience of health anxiety in clinical and nonclinical populations (e.g., Norton et al., 2005; Sexton et al., 2003). Anxiety sensitivity, which has been shown to relate to Panic Disorder, is also associated with higher levels of health anxiety (Olatunji et al., 2009). However, it remains uncertain whether other variables may moderate the relations between this variable and health anxiety.

Although anxiety sensitivity (e.g., Olatunji et al., 2009) consistently accounts for scores on health anxiety measures, the association between intolerance of uncertainty and health anxiety remains unclear. Intolerance of uncertainty has been extensively studied as a contributing factor to GAD, only recently becoming a focus of health anxiety research. Some studies have demonstrated that intolerance of uncertainty is related to health anxiety (Deacon \& Abramowitz, 2008) and fear of illness (Carleton et al., 2007), while others studies do not support a relation between intolerance of uncertainty and health anxiety (Norton et al., 2005; Sexton et al., 2003). Additionally, it is unclear whether other variables may account for the relation between intolerance of uncertainty and the experience of health anxiety, as no studies have examined variables that moderate this relation.

Countless variables have been shown to relate to various forms of anxiety, yet have not been examined in relation to health anxiety. Of particular interest, the relations between health anxiety and emotion regulation and perceived anxiety control have not been directly studied. It also remains unknown whether these variables moderate the relations between health anxiety and other variables. However, these variables have been examined as intermediate variables with respect to other anxiety disorders (e.g., Panic Disorder). For example, anxiety control mediates the relation between anxiety sensitivity and anxiety symptoms in children and adolescents (Marin et al., 2008). Additionally, emotion regulation accounts for fear of body sensations in 
individuals with panic attacks (Tull et al., 2008). Finally, the emotion regulation strategies of suppression and reappraisal moderate the relations between health anxiety and (a) general anxiety and (b) anxiety sensitivity, respectively (Gerolimatos \& Edelstein, in preparation).

While it is important to understand which variables contribute to health anxiety, it is also important to determine the extent to which these variables contribute to health anxiety in older and younger adults. Age-related differences have been found in the presentation of symptoms (Brenes et al., 2008) and the physiological experience of anxiety (Teachman \& Gordon, 2009) in young and older adults with anxiety disorders (e.g., GAD and panic). Further, older adults are less accurate at identifying the symptoms of anxiety relative to younger age groups (Wetherell et al., 2009). Therefore, there may also be age-related differences in the presentation and experience of health anxiety in older and younger adults. Only one study has directly compared older and younger adults on the severity of health anxiety (Bourgault-Fagnou \& Hadjistravopoulos, 2009). This study focused on the extent to which frailty and emotional preoccupation accounted for scores on a measure of health anxiety, but also explored the relations between a measure of health anxiety and depression, trait anxiety, and pain. Another study of health anxiety examining only older adults investigated how various demographic factors (e.g., education level, gender) and health status related to health anxiety (Boston \& Merrick, 2010). Beyond these two studies, health anxiety is virtually unstudied in older adults.

To summarize, little is known about health anxiety in young adults, and even less is known about health anxiety among older adults. Considerable research on younger adults has supported a relation between health anxiety and anxiety sensitivity, such that many individuals who are high on a measure of health anxiety are also high on a measure of anxiety sensitivity (e.g., Olatunji et al., 2009). The relation between health anxiety and intolerance of uncertainty 
has also been studied in young adults, although it remains unclear as to what role intolerance of uncertainty plays in accounting for health anxiety (Sexton et al., 2003; Deacon \& Abramowitz, 2008). Additional variables for consideration have been explored in relation to the anxiety disorders (e.g., GAD, OCD, and Panic Disorder) yet have not been examined as potential contributors to the experience of health anxiety. Specifically, little or no research has explored the possible roles emotion regulation and perceived anxiety control in accounting for levels of health anxiety. Furthermore, the natures of the relations among anxiety-related constructs and health anxiety have not been extensively explored, and it is unknown how these variables relate to the cognitive-behavioral model of health anxiety. A greater understanding of how these variables may account for health anxiety may alter how researchers and clinicians currently conceptualize the disorder. Presently, there remains much to be learned about health anxiety.

\section{The Present Study}

Given the paucity of research on health anxiety, the present study was largely exploratory in nature. This study had four main aims: (1) determine the range and distribution of scores on a measure of health anxiety in older and younger samples, (2) examine factors related to health anxiety, as measured by the Short Health Anxiety Inventory (SHAI; Salkovskis et al., 2002), (3) identify variables that may act as moderators in accounting for health anxiety, and (4) explore possible age-related differences in the factors contributing to health anxiety. The variables examined in this study included anxiety sensitivity, intolerance of uncertainty, anxiety control, and emotion regulation, in order to better understand health anxiety in older and younger adults as well as factors that influence the experience of health anxiety and its presentation.

With respect to the first aim, this study examined the following questions: (Q1) What is the range and distribution of scores on the SHAI, a measure of health anxiety, in a sample of 
younger adults? (Q2) What is the range and distribution of scores on the SHAI in a sample of older adults? (Q3) Is one age group more health anxious than the other? This comparison of scores on a measure of health anxiety between older and younger was a replication of the Boston and Merrick (2010) study with older adults and an extension to younger adults.

To address the second aim, I examined factors that have been shown to relate to scores on measures of anxiety disorders (e.g., Panic Disorder, GAD, and OCD). In particular, I focused on emotion regulation, anxiety sensitivity, perceived anxiety control, and intolerance of uncertainty, as factors contributing to SHAI scores for both older and younger adults. Additional research questions included: (Q4) Does anxiety sensitivity account for SHAI scores? Examination of this question replicated previous research on health anxiety in young adults by Olatunji and colleagues (2009) and expanded upon Sexton et al. (2003), who demonstrated a relation between anxiety sensitivity scores and scores on the Illness Attitudes Scale (IAS; Kellner, Abbott, Winslow, \& Pathak, 1987), a measure of the health anxiety, in young adults. (Q5) Does intolerance of uncertainty also contribute to SHAI scores? This relation has been demonstrated in studies by Deacon and Abramowitz (2008) in a clinical population and Carleton and colleagues (2007) in young adults. (Q6) Does emotion regulation account for SHAI scores in both age groups? Exploration of the link between emotion regulation and health anxiety expanded upon previous research examining the role of emotion regulation in explaining the anxiety disorders and symptoms of anxiety (e.g., Gould \& Edelstein, 2010; Mennin et al., 2009). (Q7) Does anxiety control relate to health anxiety? A focus on anxiety control and its relation to health anxiety expanded upon research on social anxiety (Hofmann, 2005), and worry (Gould \& Edelstein, 2010). Overall, these questions will add to the cognitive-behavioral model of health anxiety by identifying cognitive variables that contribute to perceived illness likelihood and 
negative consequences of an illness. Illness likelihood and negative consequences are two components of the model that are conceptually related to the onset of health anxiety.

To address the third aim, the research questions included: Does emotion regulation moderate the relation between health anxiety and (Q8) anxiety sensitivity? and (Q9) intolerance of uncertainty? In addition, other research questions included: Does anxiety control moderate the relation between health anxiety and (Q10) anxiety sensitivity? and (Q11) intolerance of uncertainty? Most research has examined emotion regulation and anxiety control as mediators (e.g., Gould \& Edelstein, 2010; Marin et al., 2008). However, the cognitive-behavioral model suggests that these variables may instead moderate the relations between anxiety-related constructs and health anxiety. That is, anxiety control and emotion regulation can be conceptualized as coping factors in the cognitive-behavioral model. Coping factors appear to attenuate the relations among the factors in the model, thereby contributing to the maintenance of health anxiety. Based on this model, emotion regulation and anxiety control may moderate the relations between anxiety-related factors and health anxiety. Further, Gerolimatos and Edelstein (in preparation) demonstrated that the emotion regulation strategies of reappraisal and suppression moderate the relation between anxiety-related constructs and health anxiety. Therefore, anxiety control and emotion regulation were tested as moderators. I explored emotion regulation and anxiety control as coping factors because these constructs have established relations with the anxiety disorders that share similar features with health anxiety, and have also been shown to relate to lower levels of anxiety-related symptoms (e.g., Marin et al., 2008; Tull et al., 2008). This research question expands upon previous work (e.g., Norton et al., 2003) by examining the nature of the relations among anxiety-related constructs and health anxiety in both older and young adults. 
To address the fourth aim, the final research question was (Q12) Do the variables accounting for health anxiety differ for older and younger adults? Research on health anxiety in older age groups is limited, as there are only two studies to our knowledge that directly examine health anxiety in older adults (Boston \& Merrick, 2010; Bourgault-Fagnou and Hadjistavropoulos, 2009). Therefore, the present study on health anxiety with this population will expand upon the findings of these studies. Overall, the results of this study will contribute to a greater understanding of factors relating to health anxiety in older and younger adults.

\section{Methods}

\section{Participants}

Eighty-six older adults aged 60 and older and 119 young adults between the ages of 18 and 30 years old participated in this study. Two young adult participants were dropped from analyses due to failure to complete a sufficient percentage of the surveys, leaving a total of 117 young adult participants. No other cases were dropped. There were 45 older adult females (52\%) and 60 young adult females (51\%). Mean age for the older adult group was 69.94 years $(S D=$ $8.11)$, and mean age for the younger adults was 20.42 years $(S D=2.13)$. The majority of participants were Caucasian, with 82 older adults (95\%) and 109 younger adults (93\%) indentifying as white. Other ethnicities included African American (two older adults and three younger adults), Asian American (four younger adults), Latino (two younger adults), and Native American (three younger adults). One older adult and two younger adults identified as "other." Participants were permitted to endorse more than one option for ethnicity.

Age groups significantly differed on years of education, $t(198)=2.37, p<.05$, with older adults $(M=15.15, S D=3.54)$ reporting slightly more years of education than young adults $(M=14.30, S D=1.35)$. Older adults also reported greater health problems $(M=5.63, S D=4.12)$ 
than younger adults $(M=3.16, S D=2.69)$, which was significant, $t(199)=5.14, p<.01$. Finally, significant differences were found for income level, with more young adults reporting higher family incomes, $X^{2}(3, N=203)=25.06, p<.01$.

Younger participants were recruited from undergraduate and graduate level psychology courses at West Virginia University. Each participant was compensated with extra credit in the course. Older adults were recruited via fliers posted at local senior centers and independent living facilities, as well as cable television and intra-net announcements. Older participants were compensated with $\$ 5$ for completing the surveys.

\section{Dependent Measure}

Short Health Anxiety Inventory (SHAI; Salkovskis, et al., 2002). The SHAI is an 18item self-report measure that assesses symptoms of health anxiety across the full range of severity (not at all anxious to hypochondriasis) for the past six months (see Appendix A). The SHAI is comprised of two factors: Illness Likelihood, which is assessed with items 1-14, and Negative Consequences, which assesses the impact a serious illness would have on an individual's life (items 15-18). Although there is no cut-off score for the diagnosis of health anxiety, higher scores indicate more severe health anxiety. The SHAI demonstrates excellent internal consistency ( $\alpha=.96$; Abramowitz, Deacon, \& Valentiner, 2007). It is moderately associated $(r=.63)$ with another measure of health anxiety, the Illness Attitude Scale (Kellner et al., 1987). It is moderately associated with the Beck Anxiety Inventory (BAI; Beck \& Steer, 1990) and the Social Interaction Anxiety Scale (Mattick \& Clark, 1998), with an $r$ of .42 for both scales (Abramowitz, Deacon, \& Valentiner, 2007). It also distinguishes between those with trait anxiety, social anxiety, and physical illness (Salkovskis et al., 2002). Test-retest reliability has not been examined with the SHAI, but the long version demonstrates adequate test-retest 
reliability in a clinical population $(r=.90$; Salkovskis et al., 2002). In the present sample, Cronbach's alphas for the SHAI full scale ( $\alpha=.90$ for older adults and $\alpha=.86$ for young adults), Illness Likelihood subscale ( $\alpha=.89$ for older adults and $\alpha=.87$ for young adults), and Negative Consequences subscale ( $\alpha=.76$ for older adults and $\alpha=.66$ for young adults) were adequate.

\section{Independent Measures}

Demographics. To gain descriptive information about the sample, each participant completed a demographics questionnaire, which asked for information regarding age, gender, ethnicity (race), marital status, years of education, current job status, and number of health problems (see Appendix B).

Short Form Health Survey (SF-12; Ware, Kosinski, \& Keller, 1996). To control for health problems, which may account for higher scores on measures of health anxiety, the SF-12 was administered to all participants. The SF-12 is a twelve item self-report measure derived from the Medical Outcomes Study 36-Item Short Form Health Survey (Ware \& Sherbourne, 1992). The measure is comprised of two subscales, the Physical Component Summary and the Mental Component Summary, which have demonstrated strong correlations with the same subscales on the SF-36 $(r=.91$ for the Physical Component Summary and $r=.92$ for the Mental Component Summary; Ware, et al., 1996). Two-week test-retest reliability of the survey is high ( $r=.89$ and $r$ $=.76$ for Physical and Mental subscales respectively). Discriminant validity has been established using a known groups procedure, which assesses the extent to which scores on the SF-12 differentiate among demographic variables (e.g., gender, age, presence of depression and/or anxiety, etc.) that are known to be related to physical and mental health (Ware et al., 1996). Items on the SF-12 ask about general overall health, pain, emotional problems, and physical health (see Appendix C). Higher scores indicate better overall health. 
Anxiety Sensitivity Index (ASI; Reiss, Peterson, Gursky, \& McNally, 1986). The ASI is a 16-item measure that assess fear of anxiety symptoms. In particular, this measure asks participants to rate fear of various consequences resulting from anxious arousal, such as appearing nervous and feeling faint. Psychometric properties of this measure are adequate (Reiss et al., 1986). Numerous examinations have established evidence for divergent validity through the demonstration of relatively low correlation coefficients ( $r$ ranging from 0 to .36; Reiss, 1991) with the State-Trait Anxiety Inventory (a measure of trait anxiety; Spielberger, Gorsuch, \& Luchene, 1970). Evidence for convergent validity has been established through correlations between the ASI and the Fear Survey Schedule (Wolpe \& Lang, 1964) in a sample of college students, with $r$ ranging from .59 to .71 . The ASI has also been used in studies on a variety of age groups (e.g., Deer \& Calamari, 1998; Teachman \& Gordon, 2009), and has Cronbach's $\alpha$ in a combined sample of older and younger adults of .84 (Teachman \& Gordon, 2009). In a sample of college students, two-week test-retest reliability was sufficient (is $r=.75$; Reiss et al., 1986). Cronbach's alpha in the current study was .91 for older adults and .91 for young adults. The ASI is presented in Appendix D.

Intolerance of Uncertainty Scale (IUS; Freeston et al., 1994). The IUS is a 27-item measure assessing the extent to which a person feels that uncertainty is acceptable (see Appendix H). Each item is rated with a Likert-type scale, ranging from 1 ("not at all characteristic of me") to 5 ("entirely characteristic of me"). Higher scores indicate higher levels of intolerance of uncertainty. Psychometric properties of the measure have been examined. The IUS demonstrates high internal consistency $(\alpha=.94)$ and five-week test-retest reliability $(r=.74$; Buhr $\&$ Dugas, 2002). Lastly, relations between the IUS, Beck Depression Inventory-II (Beck, Steer, \& Brown, 1996) and BAI (Beck \& Steer, 1990) suggest adequate discriminant validity for the IUS ( $r=.59$ 
and $r=.55$, respectively; Buhr \& Dugas, 2002). Cronbach's alphsa was .95 for the older adults and .97 young adults in the present study. See Appendix E for the IUS.

Emotion Regulation Questionnaire (ERQ; Gross \& John, 2003). The ERQ is a 10-item measure of emotion regulation strategies. In particular, this measure assesses suppression (inhibiting the expression of emotions) and reappraisal (reducing the impact of the emotion by thinking about the event differently). In an undergraduate sample, internal consistency for reappraisal $(\alpha=.79)$ and suppression $(\alpha=.73)$ are adequate (John \& Gross, 2004), as was the three-month test-retest reliability ( $r=.69$ for both subscales; John \& Gross, 2004). The ERQ has also been evaluated with middle-aged women, yielding $\alpha$ of .76 and .64 for the Reappraisal and Suppression subscales, respectively (John \& Gross, 2004). Discriminant validity has been established with respect to positive and negative affect, the Big Five personality traits, and coping methods (see Gross \& John, 2003). For example, the Reappraisal and Suppression subscales are only moderately related to positive affect ( $r=.42$ and $r=-.33$ respectively), and negative affect ( $r=-.51$ for Reappraisal and $r=.39$ for Suppression; Gross $\&$ John, 2003) as measured by the PANAS (Watson, Clark, \& Tellegen, 1988). In this study, internal consistency was adequate for the older adults ( $\alpha=.78$ for reappraisal and $\alpha=.79$ for suppression) and young adults ( $\alpha=.87$ for reappraisal and $\alpha=.76$ for suppression). The ERQ is shown in Appendix F.

Anxiety Control Questionnaire (ACQ; Rapee, Craske, Brown, \& Barlow, 1996). The ACQ is a 30-item self-report measure assessing one's perceived ability to control anxious situations and emotional reactions to these situations. Higher scores indicate greater perceived control. Factor analysis indicates that the ACQ consists of three subscales: internal sense of control, control over internal events, and control over external events (Zebb \& Moore, 1999). Internal consistency of the scale in both clinical and undergraduate samples is high, with $\alpha$ 
ranging from .80 to .87 , and from .82 to .89 , respectively (Rapee et al., 1996). One week ( $r=$ $.88)$ and one month $(r=.82)$ test-retest reliability is also adequate (Rapee et al., 1996).

Comparisons to the Depression Anxiety Stress Scale (DASS; Lovibond \& Lovibond, 1995) have provided evidence for divergent validity (Rapee et al., 1996). The ACQ is only moderately related to the DASS-Anxiety subscale $(r=-.46)$, the DASS-Depression subscale $(r=-.47)$, and the DASS-Stress subscale $(r=-.51)$. ACQ scores are correlated with scores on the Locus of Control of Behavior Scale ( $r=.77$; Craig, Franklin, \& Andrews, 1984), providing some support for the convergent validity of the ACQ. Internal consistency was adequate in this sample of older adults $(\alpha=.70)$ and young adults $(\alpha=.77)$. See Appendix G for the ACQ.

\section{Procedure}

Young adult participants completed surveys on a web-based agent. Potential participants were first presented with a cover letter explaining the purpose, risks, and benefits of the study. Individuals who agreed to participate after reading the cover letter were immediately administered the surveys. All of the following surveys were presented in a random order so as to diminish order effects: Demographics, SF-12, SHAI, ASI, IUS, ERQ, and ACQ.

Interested older adult participants who called or emailed the researchers were mailed a packet of surveys. The order of the surveys was also randomized. With the packet was a consent form articulating the purposes and procedures of the study and a pre-stamped and addressed return envelope. Participants were compensated with $\$ 5$ at the time the surveys were mailed.

\section{Results}

\section{Missing Data, Outliers, and Skew}

Prior to conducting analyses, missing data were examined. Data of participants who answered at least 70 percent of each survey were kept for subsequent analyses. One young adult 
participant was dropped from all analyses due to failure to complete several of the measures. Another young adult answered only three items of the SHAI. Because the SHAI is the criterion variable, this participant was also dropped from analyses. Two older adult participants did not complete the ASI, but data from these two participants were kept for analyses. For these two participants, the ASI scores were estimated via regression in which ASI scores were predicted based on the individual's scores on the other completed measures. Because less than 5 percent of the data were missing, missing scale items were replaced with each participant's mean for the items on each scale. With few data missing, mean imputation is considered an appropriate data replacement strategy (Tabachnick \& Fidell, 2007).

The data were examined for outliers. As recommended by Tabachnick and Fidell (2007), outliers are defined as scores greater or less than 3.2 standard deviations from the mean. Observed scores that met these criteria were replaced with the highest or lowest value within 3.2 standard deviations from the mean. For example, if the value 3.2 standard deviations above the mean was 25, any outlier that was higher than this value would be replaced with a score of 25 . Similarly, if the value 3.2 standard deviations below the mean was 12 , a score that was lower than this score would be replaced with a score of 12. The ACQ and both of its subscales, and the Suppression subscale of the ERQ did not have any outliers. Only one participant was an outlier on two scales.

Each variable was examined for normality via histogram and skewness statistic. As recommended by Tabachnik and Fidell (2007), variables demonstrated considerable skew when the ratio of the skewness statistic to the standard error exceeded the absolute value of two. The following scales scores demonstrated problematic positive skew: SHAI (and both of its subscales), ASI, and IUS. Each of these scale scores was transformed using square root 
transformation, except for the IUS and negative consequences subscale of the SHAI, which required $\log$ transformations. MCS and PCS scores demonstrated negative skew, and were transformed by taking the square root of the value subtracted from a constant (the largest observed value plus one). All subsequent regression analyses were conducted twice, with transformed and non-transformed variables. Because no differences in the results were found, only results from analyses utilizing the non-transformed variables are presented.

\section{Preliminary Analyses}

Descriptive statistics for the independent variables were generated for each age group (see Table 1). To address questions 1 and 2, mean, standard deviation, and range of scores on the SHAI were generated for both age groups. For SHAI scores, older adults $(M=11.23, S D=6.97)$ reported lower mean scores than younger adults $(M=14.68, S D=6.97)$. The range of scores for both age groups was comparable. Both age groups reported maximum scores of 35 . In the older adult group, the minimum score was zero, and for young adults the minimum was one.

Pearson correlation analyses (see Table 2) were conducted to examine potential problems with multicolinearity and to explore the relations between the variables of interest (i.e., the SHAI and the independent variables). None of the correlation coefficients for the relations between the independent and dependent variables exceeded .80 (Tabachnik \& Fidell, 2007), suggesting no problems with multicolinearity. Colinearity diagnostics, including tolerance and variance inflation factor (VIF) also did not indicate problems with instability. Significant associations between health anxiety and anxiety sensitivity, $r=.54, \mathrm{p}<.01$, intolerance of uncertainty, $r=.57$, $\mathrm{p}<.01$, perceived anxiety control, $r=-.47, \mathrm{p}<.01$, and reappraisal, $r=-.19, \mathrm{p}<.01$, were found. Notably, suppression as an emotion regulation strategy was not associated with health anxiety or the subscales of the SHAI. Pearson correlation coefficients for older and younger 
adults are presented separately in Tables 3 and 4 respectively.

To determine if one age group reported greater health anxiety than the other (Q 3), an independent-samples t-test was conducted on SHAI scores. Results showed that younger adults reported significantly higher levels of health anxiety compared to older adults, $t(201)=3.49, p<$ .01. Younger adults also had significantly higher scores than older adults on the SHAI subscales: illness likelihood, $t(201)=3.01, p<.01$, and negative consequences, $t(201)=3.31, p<.01$. Additional t-tests examining the independent variables revealed that young adults reported significantly higher levels of anxiety sensitivity, $t(201)=2.30, p<.05$, and intolerance of uncertainty, $t(201)=3.86, p<.01$, whereas older adults reported higher perceived anxiety control, $t(201)=3.14, p<.01$, and use of reappraisal as an emotion regulation strategy, $t(201)=$ 2.76, $p<.01,($ see Table 1$)$.

\section{Hierarchical Regression Analyses}

To determine the extent to which each of the independent variables (anxiety sensitivity, intolerance of uncertainty, emotion regulation, and perceived anxiety control) accounted for scores on the SHAI, a hierarchical regression analysis was conducted (Q 4 through Q 7). In the first step of the regression analysis, physical health (i.e., PCS) and mental health (i.e., MCS) scores were entered as controls. Controlling for physical and mental health is important because greater health problems are related to higher levels of health anxiety. Further, there were significant associations between MCS and SHAI scores, and significant correlations between the illness likelihood subscale scores of the SHAI and PCS scores. In step two, demographic variables, including age group (older vs. younger), gender, income, and education, were entered. The independent variables (ASI, ACQ, IUS, reappraisal and suppression), were entered in step three. Each of the independent variables was centered (the mean subtracted from each 
observation), to reduce potential problems with multicolinearity. Then, each centered variable was multiplied by age, which was dummy-coded. These interaction terms were entered into step four of the hierarchical regression analysis.

The first hierarchical regression analysis included total SHAI scores as the criterion variable (see Table 5). The variables in the equation explained a substantial proportion of the variance in health anxiety, $R^{2}=.53, F(16,12.39), p<.01$. None of the demographic variables, including age group, significantly contributed to health anxiety. Anxiety sensitivity, $\beta=.48, p<$ .01 , and reappraisal, $\beta=.21, p<.05$, also significantly contributed to health anxiety. No interactions with age were significant, however, the interaction between reappraisal and age neared significance, $\beta=-.17, p=.07$.

In light of the $p$ values, I conducted exploratory regression analyses with each age group separately to better understand how the variables contribute to health anxiety in the age groups. Physical and mental health scores were entered in step one, demographic variables (gender, education, and income) were entered in step two, and the independent variables were entered in step three. Results revealed that reappraisal significantly contributed to health anxiety for older adults only, $\beta=.22, p<.01$. Reappraisal did not contribute to health anxiety for younger adults, $\beta=-.03, p=.77$. In other words, older adults who used reappraisal infrequently demonstrated lower levels of health anxiety than older individuals who used reappraisal frequently, whereas younger adults did not differ in health anxiety regardless of reappraisal use (see Figure 1).

Additional age differences were noted. With SHAI full scale scores as the criterion variable for younger adults, both anxiety sensitivity, $\beta=.29, p<.01$, and intolerance of uncertainty, $\beta=.29, p<.01$, significantly accounted for health anxiety. Results for older adults showed that anxiety sensitivity significantly contributed to health anxiety, $\beta=.48, p<.01$, 
whereas intolerance of uncertainty did not, $\beta=.21, p=.07$. The regression analysis with younger adults revealed that physical health did not contribute to health anxiety, $\beta=-.02, p=.78$, though physical health significantly contributed to health anxiety for older adults, $\beta=-24, p<.01$. The variables in the equations explained a significant proportion of the variance in health anxiety for both older, $R^{2}=.68, F(10,14.25), p<.01$, and younger, $R^{2}=.39, F(10,6.72), p<.01$, adults.

I conducted a second hierarchical regression analysis with illness likelihood scores as the criterion variable. In step one of the regression analysis, physical and mental health scores were entered. I entered age, education, income, and gender in step two, and anxiety sensitivity, intolerance of uncertainty, anxiety control, reappraisal and suppression in step three. In step four, interactions of age with all of the variables from step three were included. Interactions were created by multiplying the centered independent variables by age, which was dummy coded. The amount of variance in illness likelihood explained by the included variables was substantial, $R^{2}=$ $.49, F(16,10.73), p<.01$. Both physical health, $\beta=-.18, p<.01$, and mental health, $\beta=-.38, p$ $<.01$, accounted for illness likelihood scores, and none of the demographic variables contributed to illness likelihood scores. Again, anxiety sensitivity, $\beta=.46, p<.01$, and reappraisal, $\beta=.26, p$ $<.01$, significantly contributed to the illness likelihood scores. The only significant interaction was reappraisal by age, $\beta=-.19, p=.05$.

Exploratory hierarchical regression analyses examining each age group separately were conducted. Reappraisal significantly contributed to illness likelihood in older adults only, $\beta=$ $.27, p<.01$. That is, older adults who endorsed more use of reappraisal demonstrated higher concern regarding the likelihood of an illness than those who used reappraisal less often. No differences were found for younger adults with different levels of reappraisal use, $\beta=-.01, p=$ .96 (see Figure 2). Anxiety sensitivity also significantly contributed to illness likelihood for older 
adults, $\beta=.48, p<.01$, and younger adults, $\beta=.34, p<.01$. Notably, physical health did not significantly contribute to health anxiety for young adults, $\beta=-.07, p=.43$, but it did for older adults, $\beta=-.28, p<.01$. The included variables explained a considerable proportion of the variance in illness likelihood for older adults, $R^{2}=.66, F(10,13.17), p<.01$, and younger adults, $R^{2}=.35, F(10,5.81), p<.01$.

Finally, negative consequences subscale scores were examined as the criterion variable in a hierarchical regression analysis. In step one, PCS and MCS scores were entered. In step two, age group, gender, education, and income were entered. In step three, anxiety sensitivity, intolerance of uncertainty, reappraisal, suppression, and anxiety control were entered. Finally, step four contained interactions of age by each variable from step three. A moderate amount of variance in negative consequences was explained by the regression model, $R^{2}=.34, F(16,5.72)$, $p<.01$. Anxiety sensitivity, $\beta=.32, p<.01$, and intolerance of uncertainty, $\beta=.40, p<.05$ significantly contributed to negative consequences. The interaction between age and anxiety sensitivity in accounting for negative consequences was also significant, $\beta=-.26, p<.05$. No other significant variables or interactions were found.

Because of the significant interaction term, the interaction between anxiety sensitivity and age was further explored in each age group separately. Step one included PCS and MCS scores, step two contained gender, education, and income, and step three contained anxiety sensitivity, intolerance of uncertainty, reappraisal, suppression, and anxiety control. The overall model accounted for a significant proportion of negative consequences scores in both older adults, $R^{2}=.41, F(10,4.74), p<.01$, and younger adults, $R^{2}=.31, F(10,4.79), p<.01$. Anxiety sensitivity significantly contributed to negative consequences for older adults only, $\beta=.32, p<$ .01. Regardless of anxiety sensitivity levels, young adults did not differ with respect to negative 
consequences, $\beta=.02, p=.84$ (see Figure 3 ). Intolerance of uncertainty contributed to negative consequences scores for young adults, $\beta=.49, p<.01$, but not for older adults, $\beta=.30, p=.06$. Given that the interaction term of age and intolerance of uncertainty was non-significant (see above), the extent to which intolerance of uncertainty contributes to negative consequences for older and young adults does not significantly differ.

Two additional age-related differences were noted. Mental health scores significantly contributed to negative consequences scores for older adults, $\beta=-.27, p<.05$, but not young adults, $\beta=.02, p=.84$. Gender emerged as a significant contributor for young adults, $\beta=.20, p$ $<.05$, but not older adults, $\beta=-.08, p=.46$. Interestingly, young males $(M=2.73, S D=1.84)$, reported higher fear of negative consequences than young females $(M=3.40, S D=2.17)$, though this mean difference was non-significant.

\section{Exploratory Moderation Analyses}

Given that previous research on the anxiety disorders has identified both emotion regulation (e.g., Gerolimatos \& Edelstein, in preparation) and anxiety control (e.g., Hofmann, 2005) as intermediate variables between anxiety-related constructs and anxiety disorders, the present study sought to better understand the nature of health anxiety by examining emotion regulation (Q 8 and 9) and anxiety control (Q 10 and 11) as moderators of the relation between anxiety-related constructs (anxiety sensitivity and intolerance of uncertainty) and health anxiety. Because none of the demographic variables were related to the criterion variables, demographic variables were dropped from subsequent analyses. However, in a regression analysis with young adults in which negative consequences was the criterion variable, gender was included as a control (see below). To test for moderation, all variables were first centered, which was accomplished by subtracting the mean from each observed score. Then, interaction terms were 
created by multiplying the two variables of interest. In the first step of the regression equation, the control variables (i.e., PCS and MCS scores) were entered. In the second step, each variable of the interaction term was included individually (e.g., reappraisal and ASI entered separately). In the third step, the interaction terms were added (e.g., reappraisal x ASI). Significant interaction terms indicate that one of the variables is the moderator.

Tests of moderation were conducted on each age group separately. First, SHAI scores were examined as the criterion variable. Because intolerance of uncertainty was not significantly related to health anxiety for older adults, only anxiety sensitivity was examined. Interaction terms of anxiety sensitivity with reappraisal (ASI x reappraisal), suppression (ASI x suppression), and anxiety control (ASI x ACQ) were created. None of the interactions were significant. With younger adults, interaction terms were created for anxiety sensitivity and reappraisal (ASI x reappraisal), suppression (ASI x suppression), and anxiety control (ASI x ACQ), as well as interaction terms for intolerance of uncertainty and reappraisal (IUS $\mathrm{x}$ reappraisal), suppression (IUS x suppression), and anxiety control (IUS x ACQ). None of the interactions were significant.

Next, illness likelihood scores were included as the criterion variable. Older and young adults were examined separately. Because only anxiety sensitivity significantly contributed to illness likelihood for both age groups, anxiety sensitivity and its interactions with reappraisal (ASI x reappraisal), suppression (ASI x suppression), and anxiety control (ASI x ACQ) were included in the regression analyses. No interactions were significant for either age group.

Negative consequences scores were then examined as the criterion variable. For older adults, interaction terms for anxiety sensitivity with reappraisal (ASI x reappraisal), suppression (ASI x suppression), and anxiety control (ASI x ACQ) were created, as only anxiety sensitivity 
contributed to negative consequences scores in earlier analyses. Only the interaction of anxiety sensitivity and anxiety control was significant, $\beta=-.27, p<.01$.

To better understand the nature of the interactions, the slopes were graphed and the significance of the slopes was tested. To test the significance of the slopes, low and high values for the moderator were first generated (e.g., low perceived anxiety control and high perceived anxiety control), which is done by adding or subtracting the standard deviation of the moderator from each centered observation of the moderator. Then, high and low values of the moderator were multiplied by the independent variable (e.g., ASI). Lastly, regression analyses were conducted with the SF-12 subscales entered in step one, the independent variable (ASI) and high or low moderator values in step two, and the new interaction term (e.g., low perceived anxiety control x ASI) in step three.

Results showed that the interaction of anxiety sensitivity with high perceived anxiety control, $\beta=-.40, p<.01$, and low perceived anxiety control, $\beta=-.36, p<.01$, were both significant. That is, the relation between anxiety sensitivity and negative consequences is influenced by the extent to which one perceives having control over one's anxiety. In general, high perceived anxiety control (compared to low perceived anxiety control) results in a greater change in negative consequences scores with increasing levels of anxiety sensitivity (see Figure 4). Higher levels of perceived anxiety control appear to attenuate the relation between anxiety sensitivity and fear of the negative consequences of an illness, such that individuals with high levels of anxiety sensitivity and high perceived anxiety control report lower fear of negative consequences compared to individuals with low perceived anxiety control.

In a hierarchical regression analysis accounting for negative consequences scores in young adults, I examined the interactions of intolerance of uncertainty with reappraisal (IUS $x$ 
reappraisal), suppression (IUS x suppression), and anxiety control (IUS x ACQ). Given that the pilot study found reappraisal moderates the relation between anxiety sensitivity and negative consequences (Gerolimatos \& Edelstein, in preparation), I also included an interaction term for anxiety sensitivity by reappraisal (ASI x reappraisal) in the present regression analysis. Because gender related to negative consequences in young adults, gender was entered as a control variable (along with PCS and MCS scores) in the first step of the hierarchical regression. The centered independent variables were entered in step two, and the interaction terms were entered in step three of the hierarchical regression analysis. Results indicated that the only significant interaction accounting for negative consequences scores was between anxiety sensitivity and reappraisal, $\beta=-.26, p<.01$.

An examination of the simple slopes revealed significant interactions of anxiety sensitivity and both low reappraisal, $\beta=-.24, p<.05$, and high reappraisal, $\beta=-.36, p<.05$. These results show that the relation between anxiety sensitivity and negative consequences depends upon the use of reappraisal as an emotion regulation strategy for young adults (see Figure 5). With increasing levels of anxiety sensitivity, low reappraisal use results in less fear of negative consequences. High use of reappraisal shows a similar pattern: higher reappraisal use is related to even lower fear of negative consequences with increasing levels of anxiety sensitivity. Specifically, younger adults who were high on anxiety sensitivity and high on the use of reappraisal demonstrated less fear of negative consequences than individuals who were high on anxiety sensitivity and low on the use of reappraisal.

\section{Discussion}

At present, only two studies have examined health anxiety in older adults (Boston \& Merrick, 2010; Bourgault-Fagnou \& Hadjistavropoulos, 2009), and few studies have examined 
anxiety-related constructs in relation to health anxiety in younger age groups. The present study examined the extent to which anxiety-related constructs relate to health anxiety in older and younger adults and to explore age-related differences in factors contributing to health anxiety. Further, this study attempted to better understand the nature of the relations among anxietyrelated constructs in accounting for health anxiety by examining the roles of moderating variables. The following section will discuss the implication of these results and offer suggestions for additional research based on the present findings.

\section{Overview of Findings}

This section summarizes the present findings and is followed by a discussion of each of these findings. An initial aim of the study was to determine whether older and younger adults differed with respect to level of health anxiety. Results showed that younger adults reported higher health anxiety than older adults, as well as higher perceived illness likelihood and fear of negative consequences of an illness. Other age-related differences are noteworthy. First, older adults demonstrated greater use of reappraisal as an emotion regulation strategy and had greater perceived control of anxiety relative to young adults. Conversely, younger adults reported higher levels of anxiety sensitivity and intolerance of uncertainty than older adults.

A second aim of the study was to determine the extent to which various anxiety-related constructs relate to health anxiety. Anxiety sensitivity emerged as a contributing factor to illness likelihood in both age groups. Anxiety sensitivity did not significantly contribute to negative consequences for younger adults, though it did for older adults. Intolerance of uncertainty was also examined. Intolerance of uncertainty did not significantly account for negative consequences in older adults, though it did contribute to health anxiety and negative consequences in younger adults. Yet, the difference in the extent to which intolerance of 
uncertainty contributed to negative consequences was not significantly different between the age groups. Finally, reappraisal was a significant contributor to health anxiety and illness likelihood for older adults, but not for younger adults.

A third aim was to better understand the nature of the relations among the anxiety-related constructs in accounting for health anxiety by examining moderating variables. In older adults, the relation between anxiety sensitivity and negative consequences was moderated by perceived anxiety control, such that high anxiety sensitivity and greater anxiety control contributed to lower fear of negative consequences. For younger adults, reappraisal moderated the relation between anxiety sensitivity and fear of negative consequences. Generally, higher levels of anxiety sensitivity and greater use of reappraisal was associated with lower levels of health fear of negative consequences in young adults.

\section{Age Differences}

One of the prominent questions was whether one age group reported higher levels of health anxiety. Results showed that younger adults reported higher levels of health anxiety compared to older adults. Intuitively, one may expect older adults to endorse elevated levels of health anxiety given higher rates of health problems and use of medical services, but this was not supported. Only two studies have examined health anxiety in older adults. Bourgault-Fagnou and Hadjistavropoulos (2009) demonstrated that older adults reported lower levels of health anxiety compared to younger adults, whereas Boston and Merrick (2010) found that older adults had comparable levels of health anxiety to younger adults. Yet, Boston and Merrick examined only older adults and compared their scores on a measure of health anxiety to normative data on younger adults. Moreover, research on the anxiety disorders suggests that older adults generally have lower levels of anxiety relative to young adults (e.g., Basevitz et al., 2008; Wolitzky-Taylor 
et al., 2010). The present results are consistent with Bourgault-Fagnou and Hadjistavropoulos (2009) and research on the anxiety disorders and suggest that other factors may relate to level of health anxiety.

Older adults reported greater emotion regulation skills compared to younger adults. Numerous studies have demonstrated that emotion regulation skills increase in late life (e.g., Blanchard-Fields et al., 2004; Charles \& Carstensen, 2007). For example, research shows that older adults use the emotion regulation strategy of reappraisal more frequently and effectively than younger adults (see John \& Gross, 2004). In addition, research suggests that the age-related increase in emotion regulation is associated with decreased psychological distress (e.g., Gross \& John, 2003). The results of the present study are consistent with previous findings. Older adults also demonstrated greater perceived anxiety control than younger adults. Only one study to my knowledge has examined anxiety control in older adults (Gould \& Edelstein, 2010), which did not find significant differences in perceived anxiety control between age groups. Results from the present study are inconsistent with those of Gould and Edelstein, though this difference may be related to the fact that the mean age of the older adults in the present study was lower than the mean age of the older adult sample in the study by Gould and Edelstein. Yet, the present results appear to fit with literature suggesting enhanced regulatory processes and decreased negative affect in late life (Charles \& Carstensen, 2007). Based on these results and the foregoing literature, it appears enhanced emotion regulation and perceived anxiety control may relate to low levels of health anxiety among older adults.

Finally, younger adults exhibited higher scores than older adults on measures of two anxiety-related constructs: anxiety sensitivity and intolerance of uncertainty. Very few studies have directly compared older and younger adults on these two constructs. One study (Basevitz et 
al., 2008) found that older adults reported significantly less intolerance of uncertainty than younger adults, which was supported by the present results. However, the present results for anxiety sensitivity are inconsistent with those of Teachman and Gordon (2009), who did not find significant age differences on mean Anxiety Sensitivity Index scores. The mean scores on the ASI for the older adults in both studies were comparable, but Teachman and Gordon reported lower ASI scores for the young adults than the present study. This difference in results between the two studies may be related to sample characteristics. The Teachman and Gordon study had considerably more females than the present study, and participants were excluded for significant health problems, including poor vision and hearing, severe asthma, epilepsy, motion sickness, and cardiovascular disease, leaving a relatively healthy sample that may not experience many body sensations. Given higher prevalence rates of anxiety disorders in young compared to older adults (e.g., Wolitzky-Taylor et al., 2010), one may expect anxiety-related constructs, such as anxiety sensitivity and intolerance of uncertainty, to also be elevated among young adults. Additionally, emotion-focused regulation skills tend to be infrequently used by young adults (Blanchard-Fields et al., 2004) and are less successful in reducing negative emotions (Phillips, Henry, Hosie, \& Milne, 2008) for younger adults compared to older adults, which could account for greater difficulties with intolerance of uncertainty and anxiety sensitivity in young adults.

\section{Anxiety-Related Constructs}

Anxiety sensitivity. Anxiety sensitivity has been examined extensively in relation to health anxiety. To date, however, no studies have examined the link between health anxiety and anxiety sensitivity in older adults. The present study replicated the findings of Oltaunji et al. (2009) and Sexton et al. (2003), who found anxiety sensitivity significantly accounted for scores on a measure of health anxiety in undergraduate college students using linear regression 
analyses. The present study also replicated and extended the results to older adults by demonstrating that levels of anxiety sensitivity relate to health anxiety. This relation between anxiety sensitivity and health anxiety in older adults is consistent with similar findings from the anxiety disorders. For example, Deer and Calamari (1998) demonstrated that anxiety sensitivity significantly accounts for panic symptomatology in older adults over 60 years old. Further, they posited that anxiety sensitivity may be an important predisposing factor for the development of panic. Given the similarities between panic disorder and health anxiety (e.g., Longley, Calamari, Wu, \& Wade, 2010), it is not surprising that anxiety sensitivity relates to both constructs. Research on clinical samples has conceptualized anxiety sensitivity as a trait-like, predisposing characteristic for the development of anxiety disorders (e.g., see Naragon-Gainey, 2010). Anxiety sensitivity may also be a predisposing factor for the development of health anxiety in older and younger adults. However, given that data on health anxiety and anxiety sensitivity were gathered concurrently for this study, it is impossible to determine based on these results whether anxiety sensitivity is, in fact, a predisposing trait for the development of health anxiety. Regardless, it appears anxiety sensitivity relates to health anxiety for older and young adults.

Intolerance of uncertainty. A second anxiety-related construct explored in the study was intolerance of uncertainty. In older adults, intolerance of uncertainty did not significantly contribute to illness likelihood or negative consequences. Intolerance of uncertainty neared significance when accounting for negative consequences, and older adults did not significantly differ from young adults in the extent to which intolerance of uncertainty contributed to negative consequences. These findings are unique in that no research to date has examined the relation between intolerance of uncertainty and health anxiety in older adults. It appears that intolerance of uncertainty does contribute to health anxiety in older adults, but to a lesser extent than 
younger adults. Based on the present study, older adults may be more tolerant of uncertainty than young adults given their enhanced emotion regulation skills and greater perceived control of anxiety relative to young adults. As articulated in the Strength and Vulnerability Integration (SAVI) model (Charles, 2010), due to past experiences, older adults have learned "what they are capable of surviving, what they need to do to feel contentment, and the actions necessary to avoid high levels of distress in their daily lives" (p. 1073). These experiences, in turn, relate to enhanced emotion regulation. Therefore, one might argue that intolerance of uncertainty plays only a minor role in health anxiety in late life because of older adults' strengths in emotion regulation.

With respect to intolerance of uncertainty in young adults, the results show that intolerance of uncertainty accounted for fear of negative consequences in young adults. Previous research has demonstrated a relation between health anxiety and intolerance of uncertainty in young adults (e.g, Carleton et al., 2007; Fergus \& Valentiner, 2009) and clinical samples (e.g., Deacon \& Abramowitz, 2008), and the present results support the notion that intolerance of uncertainty contributes to health anxiety. In an examination of young adults, Fergus and Valentiner (2009) found that intolerance of uncertainty appears to be most closely related to illness fear (worries about illness), and symptom effects (disruptive effects of an illness), but not disease conviction (likeliness beliefs). Illness likelihood is conceptually similar to disease conviction, and symptom effects are similar to fear of negative consequences, suggesting that the present findings generally support those of Fergus and Valentiner. It is important to note that the studies utilized different measures of health anxiety, and there is not perfect overlap between the constructs measured on the two scales. 
In the young adult sample, intolerance of uncertainty directly contributed to negative consequences, whereas anxiety sensitivity directly contributed to illness likelihood.

Conceptually, one may expect intolerance of uncertainty to relate to negative consequences. One could assume that potential negative outcomes of an illness are not certain. For example, it is difficult to know whether one may recover from a particular illness, how long one may be ill, or how debilitating the illness may be. Individuals who are especially intolerant of uncertainty may find this lack of predictability particularly distressing. On the other hand, one could argue that anxiety sensitivity should conceptually relate to illness likelihood. Anxiety sensitivity, by definition, is the fear of anxiety symptoms. These anxiety symptoms are often interpreted by health anxious individuals as indicative of some illness (i.e., that illness is likely; Deacon \& Abramowitz, 2008). Thus, it is not surprising that anxiety sensitivity directly explains illness likelihood. Like older adults, both anxiety sensitivity and intolerance of uncertainty may predispose young adults to develop health anxiety, though intolerance of uncertainty plays a larger role in accounting for health anxiety in young adults compared to older adults. As described earlier, young adults reported lower reappraisal and perceived anxiety control relative to older adults, which may explain greater levels of health anxiety despite having similar predisposing factors as older adults.

Reappraisal. Another variable examined as a contributing factor to health anxiety was emotion regulation. Reappraisal, one type of emotion regulation strategy, accounted for illness likelihood in older adults. However, results showed that older adults with higher use of reappraisal reported higher levels of fear of illness likelihood than older adults with low reappraisal use. These results appear counterintuitive, as many studies have found evidence that enhanced emotion regulation reduces psychological distress (e.g., Gross \& John, 2003). One 
explanation for this finding may be that older adults have greater difficulty with reappraisal of unpleasant emotions compared to other emotion regulation strategies largely because reappraisal relies on higher-order cognitive processes (e.g., attention, inhibition; Urry \& Gross, 2010). Further, effortful use of reappraisal is less successful in attenuating anxious emotions and physiological arousal than automatic, non-effortful reappraisal (Williams, Bargh, Nocera, \& Gray, 2009), suggesting that reappraisal may tax cognitive resources (i.e., is cognitively demanding). Therefore, reappraisal may not be successful in reducing anxiety in older adults due to age-related cognitive deficits, high cognitive demand, or both. This explanation is not likely; the age of the adult sample was relatively young, so cognitive impairment in this population is unlikely. Further, research shows that adults in their 60 s tend to use reappraisal frequently (Urry \& Gross, 2010), and the present sample consisted largely of adults under the age of 70 years who also reported frequent reappraisal use. Also, reappraisal is considered less cognitively demanding than suppression (John \& Gross, 2004), emphasizing the notion that reappraisal can be an effective and preferred emotion regulation strategy, especially among older adults. Another explanation may be that this particular sample of older adults has little experience with reappraising their fears of illness likelihood. The Emotion Regulation Questionnaire asks about use of reappraisal in general, accordingly, older adults may successfully use reappraisal in other situations, but not apply reappraisal to issues of health anxiety. This explanation does not fit, as older adults would likely use regulatory skills that have been successful in other situations to manage health anxiety. Alternatively, reappraisal may not be as successful in reducing health anxiety as it is with other anxiety disorders. Yet, if health anxiety is similar to the anxiety disorders, one might expect high reappraisal use to relate to reduced anxiety and arousal, as it does with the anxiety disorders (e.g., Hofmann, Heering, Sawyer, \& Asnaani, 2009). A better 
explanation may be that older adults with higher levels of illness likelihood fear use reappraisal frequently as a means of coping with their anxiety; they may continue to report relatively high levels of anxiety, but these levels are manageable because of reappraisal use. Conversely, older adults with low illness likelihood fear do not need to reappraise. This explanation fits best with present findings that older adults effectively and frequently use reappraisal.

With young adults, reappraisal moderated the relation between anxiety sensitivity and negative consequences. Results showed that the relation between anxiety sensitivity and fear of negative consequences decreased when reappraisal use was low as well as when reappraisal use was high. However, greater change in the relation between anxiety sensitivity and negative consequences was observed when reappraisal use was high compared to low. Overall, these findings were expected, as research on the anxiety disorders (e.g., see Aldao \& NolenHoeksema, 2010 for a meta-analysis) shows greater reappraisal use to be negatively associated with anxiety symptoms. Many studies have demonstrated that young adults tend to use problemfocused approaches (e.g., Blanchard-Fields et al., 2004) and are not as successful in using reappraisal as older adults (John \& Gross, 2004). Generally, research indicates that young adults are inexperienced with reappraisal, and using reappraisal can be costly for young adults in terms of cognitive load (Scheibe \& Blanchard-Fields, 2009). Young adults with low anxiety sensitivity may have few instances in which they experience anxiety and therefore, they may have little practice with using reappraisal in relation to health anxiety. When reappraisal is not used appropriately (i.e., it requires conscious effort), it can increase anxiety (Williams et al., 2009). Accordingly, young adults with low anxiety sensitivity may have to expend a great deal of effort in order to use the skill, which can have deleterious effects on levels of fear of negative consequences associated with health anxiety. Young individuals with higher levels of anxiety 
sensitivity use reappraisal frequently, and these individuals have success in using the skill to reduce fear of negative consequences.

Results of the pilot study with young adults found that reappraisal also moderated the relation between anxiety sensitivity and negative consequences, though different patterns were found. In the pilot study, fear of negative consequences increased with greater anxiety sensitivity levels for those with high reappraisal, whereas the present study found lower fear of negative consequences with increasing anxiety sensitivity levels for those with high reappraisal. However, the demographic makeup the young adult samples in both studies were different (e.g., the present study had more males and ethnically diverse individuals), which may explain the difference in results.

Suppression. Another emotion regulation strategy, suppression, did not relate to health anxiety in any statistical analysis. Current research suggests that suppression is not an effective strategy for regulating one's emotions (Gross \& John, 2003). In fact, use of suppression can paradoxically increase negative emotions for individuals reporting high levels of negative affect (Dalgleish, Yiend, Schweizer, \& Dunn, 2009). Further, another study (Hofmann et al., 2009) found that individuals who suppressed their anxious emotions during an impromptu speech exhibited greater increase in heart rate compared to individuals who engaged in reappraisal or acceptance of the emotions. Additionally, older and younger adults do not appear to differ on the use of suppression (Phillips et al., 2008), which was also supported by these data. It appears suppression is not a useful tool for reducing anxiety, and older and younger individuals with varying levels of health anxiety do not appear to employ this method differentially.

Anxiety control. Finally, anxiety control was examined. In older adults, anxiety control moderated the relation between anxiety sensitivity and negative consequences. In other words, 
the relation between anxiety sensitivity and negative consequences was influenced by one's level of perceived anxiety control. Low perceived anxiety control was associated with slight but significant decreases in fear of negative consequences as anxiety sensitivity levels increased, whereas for high perceived anxiety control, fear of negative consequences decreased dramatically as anxiety sensitivity increased. This pattern is consistent with research suggesting that enhanced self-regulatory skills are related to less psychological distress (Gross \& John, 2003). Although no studies have examined perceived anxiety control in health anxiety, these results are consistent with findings from research on anxiety symptoms and disorders, which shows that anxiety control is associated with lower levels of worry in older adults (Gould \& Edelstein, 2010) and less social anxiety in adults aged 18 to 74 (Hofmann, 2005).

Perceived anxiety control was related to negative consequences but not illness likelihood for older adults. One might argue that negative consequences of an illness are largely beyond one's control. For example, if an illness causes limitations in functional activities, there is little chance of changing this outcome. Further, it may be difficult to reappraise the negative consequences of an illness if those negative consequences are inevitable. Therefore, being able to control one's anxiety related to this inevitable outcome may be a helpful strategy in coping with the illness and may be one avenue by which one can maintain some form of control in one's life. Reappraisal, which was related to illness likelihood for older adults, appears to be more effective for reducing fear of illness likelihood for older adults. That is, when considering the likelihood that one may have an illness, it may be more helpful to change one's thinking, such as reconsidering whether the illness is actually likely or focusing on positive aspects in one's life.

For young adults, perceived anxiety control did not contribute to health anxiety, nor its subcomponents, illness likelihood and negative consequences. In addition, anxiety control did 
not mediate nor moderate the relations between any variables and health anxiety. The lack of a relation between anxiety control and health anxiety is remarkable given that greater anxiety control is associated with lower worry in young adults (Gould \& Edelstein, 2010) and less social anxiety in adulthood (Hofmann, 2005). Of note, the young adults in the Gould and Edelstein study had comparable levels of perceived anxiety control to the older adults. Because the young adults in the present sample had relatively low levels of anxiety control, anxiety control may have had little impact on health anxiety levels.

\section{Implications for the Cognitive-Behavioral Model}

The results of this study bear on the cognitive-behavioral model of health anxiety proposed by Salkovskis and Warwick (1986). As described in the introduction, this model posits that health anxiety emerges due to the interactions of (a) the perceived likelihood of the illness, (b) perceived cost (i.e., negative effects) of the illness, (c) perceived ability to cope with the illness, and (d) availability of rescue factors (e.g., cures for the illness). Notably, this model focuses heavily on cognitive factors, with little emphasis on behaviors or physiology associated with anxiety. This study explored the extent to which anxiety sensitivity and intolerance of uncertainty contribute to two primary components of health anxiety: (a) perceived illness likelihood, and (b) and negative consequences, which are directly measured by the SHAI. I also explored emotion regulation and anxiety control as potential coping factors (c). Factors related to (d) were not examined in this study. The proposed conceptual models for older and young adults are similar, as only age-related differences with respect to (c) are noted.

For ease of explanation, the proposed conceptual model for the development of health anxiety in older adults is presented in Figure 6, and a conceptual model for young adults is presented in Figure 7. For older and young adults, intolerance of uncertainty and anxiety 
sensitivity are predisposing characteristics, though intolerance of uncertainty contributes to health anxiety more for young adults than older adults. If individuals with these predispositions are subjected to a serious health problem (either in the self, vicariously through others, or in the news), anxious arousal occurs. Anxious responding is then generalized to other illness-related stimuli. When faced with these stimuli, older and younger adults consider perceived likeliness and negative consequences or costs of an illness.

In older adults, the anxious thought patterns are attenuated by coping factors, such as perceived control over anxiety (when considering negative consequences of an illness) or reappraisal skills (when considering illness likelihood). One might argue that perceived anxiety control is the result of effective coping skills (e.g., if one can regulate emotions using a given skill, one may then have a greater sense of control regarding anxiety). At present, it is unclear which particular coping skill or skills may account for the relation between anxiety control and health anxiety. For now, results suggest that perceived anxiety control appears to be a coping factor related to lower levels of health anxiety in older adults, though the nature of the relation remains uncertain. Overall, enhanced coping skills in late life may explain relatively low levels of health anxiety among older adults.

For young adults, anxious thoughts regarding negative consequences are attenuated through the lack of reappraisal skills, which is a type of coping factor. Regarding illness likelihood, young adults do not appear to use coping skills examined in this study. Moreover, perceived anxiety control is not a perceived coping factor for young adults. Again, one might assume perceived anxiety control is the outcome of effective coping, but it is unclear based on the present study which coping skill or skills accounts for perceived anxiety control. Given this 
model, younger adults may be more health anxious relative to older adults because young adults lack effective coping skills.

Although beyond the scope of this paper, safety-behaviors can also be conceptualized as coping factors, which may maintain health anxiety symptoms. As demonstrated by Abramowitz and Moore (2007), safety-behaviors, such as reassurance seeking, serve similar functions to compulsions in OCD: to alleviate anxiety. Through repeated engagement in these behaviors, anxious responding is maintained via negative reinforcement. Yet, these safety-behaviors are maladaptive, and do not reduce health anxiety in the long-term. Therefore, successful coping factors likely include reappraisal or perceived control over anxiety. Overall, the present findings support and expand upon the cognitive-behavioral model described by Salkovskis and Warwick (1986) for both older and young adults by identifying specific variables (i.e., anxiety sensitivity and intolerance of uncertainty) related to illness likelihood and negative consequences, as well as particular coping factors (i.e., reappraisal and perceived anxiety control).

\section{Implications for Conceptualization, Assessment, and Treatment}

Broad implications of this study include enhancement of our understanding and conceptualization of health anxiety. First, this study examined relations among constructs with known relations to the anxiety disorders. Results of the present study demonstrated that these factors also contribute to health anxiety, suggesting that health anxiety may be better conceptualized as an anxiety disorder rather than a somatoform disorder. Conceptualizations of health anxiety appear to be similar in both age groups, though age-related differences in how coping factors (i.e., reappraisal and anxiety control) relate to health anxiety were found. These results emphasize the importance of developing assessment batteries and interventions targeting anxiety sensitivity, intolerance of uncertainty, emotion regulation, and anxiety control, as these 
factors appear to contribute to the onset or maintenance of health anxiety. For example, therapy for health anxiety may integrate components that focus on anxiety sensitivity and intolerance of uncertainty regarding health concerns. Similarly, expanding one's emotion regulation abilities and enhancing anxiety control skills appear to be necessary components of therapeutic interventions for health anxiety, especially for young adults, as these factors appear to lessen levels of health anxiety. Finally, conceptual models, such as those discussed here, may be useful in determining and prioritizing factors on which to intervene. For example, it may be necessary to enhance a client's tolerance of uncertainty if this factor accounts for ensuing symptoms.

\section{Limitations}

A few limitations of the present study are addressed. First, demographic characteristics for both age groups do not appear to be representative of the general population. Both age groups were predominately white, and generalizations to other ethnic groups should be done with caution. The young adults group was comprised entirely of undergraduate students, who may be more educated than the general population, and the older adult sample was highly educated, so these results may not apply to less educated groups. Within the older adults, the mean age was generally low. Again, generalizing these results to the oldest old may not be possible. A final limitation is that this study relied on a single method (i.e., self-report surveys) and data were collected at a single point in time. Other methods (e.g., physiological recordings of autonomic arousal) may provide additional information regarding the relations among variables and how variables may account for health anxiety.

\section{Future Directions}

Little research on health anxiety exists, especially in older adults, leaving much to be learned. The nature of health anxiety and its presentation in clinically and ethnically diverse 
samples could be explored with a similar method. A better understanding of health anxiety could be achieved through examining other anxiety-related constructs (e.g., body vigilance, other coping strategies) in relation to health anxiety. Because the present study was one of the first (see Bourgault-Fagnou \& Hadjistavropoulos, 2009) to examine the relation between emotion regulation and health anxiety, additional strategies for regulating the experience of health anxiety could also be explored with the goal of gaining a better understanding of how young and older adults manage health-related emotions. Potential findings could apply to interventions that teach successful health anxiety regulation strategies. Researchers could also determine whether emotion regulation mediates or moderates the relations between other anxiety-related constructs and health anxiety. Tests and further development of the proposed conceptual models for older and younger adults is a next step in understanding the conceptualization of health anxiety in these age groups. For example, in order to understand effective methods for managing health anxiety symptoms, one may examine whether specific coping strategies account for the relation between perceived anxiety control and health anxiety. Similarly, examining how rescue factors map onto the proposed conceptual model, or whether exposure to health problems is a necessary component for the development of health anxiety, are possible areas of focus. Continued research that enhances our understanding of the development, maintenance, and experience of health anxiety in various age groups is needed. 


\section{References}

Abramowitz, J. S., Deacon, B. J., \& Valentiner, D. P. (2007). The Short Health Anxiety

Inventory: Psychometric properties and construct validity in a non-clinical sample. Cognitive Therapy and Research, 31, 871-883.

Abramowitz, J. S., \& Moore, E. L. (2007). An experimental analysis of hypochondriasis. Behaviour Research and Therapy, 45, 413-424.

Abramowitz, J. S., Olatunji, B. O., \& Deacon, B. J. (2007). Health anxiety, hypochondriasis, and the anxiety disorders. Behaviour Therapy, 38, 86-94.

Aldao, A., \& Nolen-Hoeksema, S. (2010). Specificity of cognitive emotion regulation strategies: A transdiagnostic examination. Behaviour Research and Therapy, 48, 974-983.

American Association for Geriatric Psychiatry (2004). Geriatrics and Mental Health—The Facts.

Retrieved on May 10, 2010 from: http://www.aagponline.org/prof/facts_mh.asp.

American Psychiatric Association (1968). Diagnostic and Statistical Manual of Mental

Disorders, Second Edition, Text Revision. Washington, D.C.: Author.

American Psychiatric Association (1980). Diagnostic and Statistical Manual of Mental

Disorders, Third Edition, Text Revision. Washington, D.C.: Author.

American Psychiatric Association (2000). Diagnostic and Statistical Manual of Mental

Disorders, Fourth Edition, Text Revision. Washington, D.C.: Author.

Asmundson, G. J. G. (2010). Is hypochodriasis an obsessive-compulsive spectrum disorder? A behavioral-genetics perspective. Symposium presented at the annual meeting of the Anxiety Disorders Association of America, Baltimore, MD.

Barksy, A. J., Frank, C. B., Cleary, P. D., Wyshak, G., \& Klerman, G. L. (1991). The relation between hypochondriasis and age. American Journal of Psychiatry, 148, 923-928. 
Baron, R. M., \& Kenny, D. A. (1986). The moderator-mediator variable distinction in social psychological research: Conceptual, strategic, and statistical considerations. Journal of Personality and Social Psychology, 51, 1173-1182.

Basevitz, P., Pushkar, D., Chaikelson, J., Conway, M., \& Dalton, C. (2008). Age-related differences in worry and related processes. International Journal on Aging and Human Development, 66, 283-305.

Beck, A. T., \& Steer, R. A. (1990). Manual for the Beck Anxiety Inventory. San Antonio, TX: Psychological Corporation.

Beck, A. T., Steer, R. A., \& Brown, G. K. (1996). Manual for the BDI-II. San Antonio, TX: The Psychological Corporation.

Bertel, O., Bühler, F. R., Kiowski, W., \& Lütold, B. E. (1980). Decreased beta-andrenoreceptor responsiveness as related to age, blood pressure, and plasma catecholamines in patients with essential hypertension. Hypertension, 2, 130-138.

Blanchard-Fields, F., \& Coats, A. H. (2008). The experience of anger and sadness in everyday problems impacts age differences in emotion regulation. Developmental Psychology, 44, 1547-1556.

Blanchard-Fields, F., Stein, F., \& Watson, T. L. (2004). Age differences in emotion-regulation strategies in handling everyday problems. Journal of Gerontology: Psychological Sciences, 59B, P261-P269.

Boston, A. F., \& Merrick, P. L. (2010). Health anxiety among older people: An exploratory study of health anxiety and safety behaviors in a cohort of older adults in New Zealand. International Psychogeriatrics, 4, 1-10.

Bourgault-Fagnou, M. D., \& Hadjistavropoulos, H. D. (2009). Understanding health anxiety 
among community dwelling seniors with varying degrees of frailty. Aging and Mental Health, 13, 226-237.

Bravo, I. M., \& Silverman, W. K. (2001). Anxiety sensitivity, anxiety, and depression in older patients and their relation to hypochondriacal concerns and medical illnesses. Aging and Mental Health, 5, 349-357.

Brenes, G. A. (2006). Age differences in the presentation of anxiety. Aging and Mental Health, 10, 298-302.

Brenes, G. A., Knudson, M., McCall, W. V., Williamson, J. D., Miller, M.E., \& Stanley, M.A. (2008). Age and racial differences in the presentation and treatment of Generalized Anxiety Disorder in primary care. Journal of Anxiety Disorders, 22, 1128-1136.

Bryant, C., Jackson, H., \& Ames, D. (2008). The prevalence of anxiety in older adults: Methodological issues and a review of the literature. Journal of Affective Disorders, 109 (3), 233-250.

Buhr, K., \& Dugas, M. J. (2002). The intolerance of uncertainty scale: Psychometric properties of the English version. Behaviour Research, 40, 931-945.

Carleton, R. N., Sharpe, D., \& Asmundson, G. J. G. (2007). Anxiety sensitivity and intolerance of uncertainty: Requisites of the fundamental fears? Behaviour Research and Therapy, $45,2307-2316$.

Carstensen, L. L. (1991). Socioemotional selectivity theory: social activity in life-span context. Annual Review of Gerontology and Geriatrics. 17, 195-217.

Chapman, L. K., Kertz, S. J., Zurlage, M. M., \& Woodruff-Borden, J. (2008). A confirmatory factor analysis of specific phobia domains in African American and Caucasian American young adults. Journal of Anxiety Disorders, 22, 763-771. 
Charles, S. T. (2010). Strength and vulnerability integration: A model of emotional well-being across adulthood. Psychological Bulletin, 136, 1068-1091.

Charles, S. T., \& Carstensen, L. L. (2007). Emotion regulation and aging. In Handbook of Emotion Regulation, J.J. Gross (Ed.), New York, NY: Guilford Press

Charles, S. T., Mather, M., \& Carstensen, L. L. (2003). Aging and emotional memory: The forgettable nature of negative images for older adults. Journal of Experimental Psychology: General, 132, 310-324.

Craig, A., Franklin, J., \& Andrews, J. G. (1984). A scale to measure locus of control of behavior. British Journal of Medical Psychology, 57, 173-180.

Dalgleish, T., Yiend, J., Schweizer, S., \& Dunn, B. D. (2009). Ironic effects of emotion suppression when recounting distressing memories. Emotion, 9, 744-749.

Deacon, B., \& Abramowitz, J. S. (2008). Is hypochondriasis related to obsessive-compulsive disorder, panic disorder, or both? An empirical evaluation. Journal of Cognitive Psychotherapy: An International Quarterly, 22, 115-127.

De Bruin, G. O., Rassin, E., \& Muris, P. (2007). The prediction of worry in non-clinical individuals: The role of intolerance of uncertainty, meta-worry, and neuroticism. Journal of Psychopathology and Behavioral Assessment, 29, 93-100.

Decker, M. L., Turk, C. L., Hess, B., \& Murray, C. E. (2008). Emotion regulation among individuals classified with and without generalized anxiety disorder. Journal of Anxiety Disorders, 22, 485-494.

Deer, T. M., \& Calamari. (1998). Panic symptomatology and anxiety sensitivity in older adults. Journal of Behavior Therapy, 29, 303-316.

Fergus, T. A., \& Valentiner, D. P. (2009). Reexamining the domain of hypochondriasis: 
Comparing the Illness Attitudes Scale to other approaches. Journal of Anxiety Disorders, 23, $760-766$.

Fink, P., Ørnbøl, E., \& Christensen, K. S. (2010). The outcome of health anxiety in primary care: A two-year follow-up study on health care costs and self-rated health. PLOS ONE, 5(3), e9873.

Fox, L. S., \& Knight, B. G. (2005). The effects of anxiety on attentional processes in older adults. Aging and Mental Health, 9, 585-593.

Freeston, M. H., Rhéaume, J., Letarte, H., Dugas, M. J., \& Labdoceur, R. (1994). Why do people worry? Personality and Individual Differences, 17, 791-802.

Garwood, M., Engel, B. T., \& Capriotti, R. (1982). Autonomic nervous system function and aging: Response specificity. Psychophysiology, 19, 378-385.

Gerolimatos, L. A., \& Edelstein, B. A. (2011). Contributing factors to health anxiety in young adults: A preliminary analysis of mediators and moderators. Manuscript in preparation.

Gould, C. E., \& Edelstein, B. A. (2010). Worry, emotion control, and anxiety control in older and young adults. Journal of Anxiety Disorders, 24, 759-766.

Gitner, G. G., Hollandsworth, J. G., \& Intrieri, R. C. (1986). Age differences in cardiovascular reactivity under active coping conditions. Psychophysiology, 23, 113-120.

Gross, J. J., \& John, O. P. (2003). Individual differences in two emotion regulation processes: Implications for affect, relationships, and well-being. Journal of Personality and Social Psychology, 85, 348-362. doi: 10.1037/0022-3514.85.2.348

Hadjistavropoulos, H. D., Craig, K. D., \& Hadjistavropoulos, T. (1998). Cognitive and behavioral responses to illness information: The role of health anxiety. Behaviour Research and Therapy, 36, 149-164. 
Hazen, R. A., Vasey, M. W., \& Schmidt, N. B. (2009). Attentional retraining: A randomized clinical trial for pathological worry. Journal of Psychiatric Research, 43, 627-633.

Hofmann, S. G. (2005). Perception of control over anxiety mediates the relation between catastrophic thinking and social anxiety in social phobia. Behaviour Research and Therapy, 43, 885-895.

Hofmann, S. G., Heering, S., Sawyer, A. T., \& Asnaani, A. (2009). How to handle anxiety: The effects of reappraisal, acceptance, and suppression strategies on anxious arousal. Behaviour Research and Therapy, 47, 389-394.

Hunt, S., Wisocki, P., \& Yanko, J. (2003). Worry and use of coping strategies among older and younger adults. Anxiety Disorders, 17, 547-560.

Jennings, J. R., Karmarck, T., Manuck, S., Everson, S., Kaplan, G., \& Salonen, J. (1997). Aging or disease? Cardiovascular reactivity in Finnish men over the middle years. Psychology and Aging, 12, 225-238.

John, O. P., \& Gross, J. J. (2004). Healthy and unhealthy emotion regulation personality processes, individual differences, and life span development. Journal of Personality, $7(6) 2,1301-1334$.

Kellner, R., Abbott, P., Winslow, W. W., \& Pathak, D. (1987). Fears, beliefs, and attitudes in DSM-III hypochondriasis. Journal of Nervous and Mental Disease, 175, 20-25.

Kogan, J. N., \& Edelstein, B. A. (2004). Modification and psychometric examination of a selfreport measure of fear in older adults. Anxiety Disorders, 18, 397-409.

Lakatta, E. G. (1993). Cardiovascular regulatory mechanisms in advanced age. Physiological Reviews, 73, 413-467.

Larcom, M., \& Isaacowitz, D. M. (2009). Rapid emotion regulation after mood induction: Age 
and individual differences. Journal of Gerontology: Psychological Sciences, 64B, 733 741.

Lees, A., Mogg, K., \& Bradley, B. P. (2005). Health anxiety, anxiety sensitivity, and attentional biases for pictoral and linguistic health-threat cues. Cognition and Emotion, 19, 453-462.

Longley, S. L., Broman-Fulks, J. J., Calamari, J. E., Noyes, R., Wade, M., \& Orlando, C. M. (2010). A taxometric study of hypochondriasis symptoms. Behavior Therapy, 41, 505514.

Longley, S. L., Calamari, J. E., Wu, K., \& Wade, M. (2010). Anxiety as a context for understanding associations between hypochondriasis, obsessive-compulsive, and panic attack symptoms. Behavior Therapy, 41, 447-460.

Lovibond, S. H., \& Lovibond, P. F. (1995). Manual for the Depression Anxiety Stress Scales. Sydney: Psychology Foundation.

Marin, C. E., Rey, Y., Nichols-Lopez, K., \& Silverman, W. K. (2008). The relations between anxiety sensitivity and anxiety control in the prediction of anxiety symptoms among children and adolescents. Behavioral and Cognitive Psychotherapy, 36, 391-402.

Mather, M., \& Carstensen, L. L. (2005). Aging and motivated cognition: The positivity effect in attention and memory. Trends in Cognitive Sciences, 9, 496-502.

Mattick, R. P., \& Clarke, J. C. (1998). Development and validation of measures of social phobia scrutiny fear and social interaction anxiety. Behaviour Research and Therapy, 36, 455470.

Mennin, D. S., McLaughlin, K. A., \& Flanagan, T. J. (2009). Emotion regulation deficits in generalized anxiety disorder, social anxiety disorder, and their co-occurrence. Journal of Anxiety Disorders, 23, 866-871. 
Naragon-Gainey, K. (2010). Meta-analysis of the relations of anxiety sensitivity to the depressive and anxiety disorders. Psychological Bulletin, 136, 128-150.

Norton, P. J., Sexton, K. A., Walker, J. R., \& Norton, G. R. (2005). Hierarchical model of vulnerabilities for anxiety: Replication and extension with a clinical sample. Cognitive Behaviour Therapy, 34, 50-63.

Noyes, R., Happel, R. L., \& Yagla, S. J. (1999). Correlates of hypochondriasis in a nonclinical population. Psychosomatics, 40, 461-469.

Noyes, R., Stuart, S. P., \& Watson, D. B. (2008). A reconceptualization of the somatoform disorders. Psychosomatics, 49, 14-22.

Nuevo, R., Wetherell, J. L., Montorio, I., Ruiz, M. A., \& Cabrera, I. (2009). Knowledge about aging and worry in older adults: Testing the mediating role of intolerance of uncertainty. Aging and Mental Health, 13, 135-141.

Olatunji, B. O., Wolitzky-Taylor, K. B., Elwood, L., Connolly, K., Gonzales, B., \& Armstrong, T. (2009). Anxiety sensitivity and health anxiety in a nonclinical sample: Specificity and prospective relations with clinical stress. Cognitive Therapy and Research, 33, 416-424.

Owens, K. M. B., Asmundson, G. J. G., Hadjistavropoulos, T., \& Owens, T. J. (2004). Attentional bias toward illness threat in individuals with elevated health anxiety. Cognitive Therapy and Research, 28, 57-66.

Palmer, B. W., Jeste, D. V., \& Sheikh, J. I. (1997). Anxiety disorders in the elderly: DSM-IV and other barriers to diagnosis and treatment. Journal of Affective Disorders, 46, 183-190.

Phillips, L. H., Henry, J. D., Hosie, J. A., \& Milne, A. B. (2008). Effective regulation of the experience and expression of negative affect in old age. Journal of Gerontology: Psychological Sciences, 63B, P138-P145. 
Rapee, R. M., Craske, M. G., Brown, T. A., \& Barlow, D. H. (1996). Measurement of perceived control over anxiety-related events. Behavior Therapy, 27(2), 279-293.

Reiss, S. (1991). Expectancy model of fear, anxiety, and panic. Clinical Psychology Review, 11, 141-153.

Reiss, S., \& McNally, R. J. (1985). In S. Reiss, \& R.R. Bootzin (Eds.), Theoretical issues in behavior therapy, p. 107-121. New York: Academic Press.

Reiss, S., Peterson, R. A., Gursky, D. M., \& McNally, R. J. (1986). Anxiety sensitivity, anxiety frequency and the prediction of fearfulness. Behaviour Research and Therapy, 24, 1-8.

Rosen, N. O., Knäuper, B., \& Sammut, J. (2007). Do individual differences in intolerance of uncertainty affect health monitoring? Psychology and Health, 22, 413-430.

Salkovskis, P. M,. Rimes, K. A., Warwick, H. M. C., \& Clark, D. M. (2002). The Health Anxiety Inventory: Development and validation of scales for the measurement of health anxiety and hypochondriasis. Psychological Medicine, 32, 843-853.

Salkovskis, P. M., \& Warwick, H. M. (1986). Morbid preoccupations, health anxiety, and reassurance: a cognitive-behavioral approach to hypochondriasis. Behavior Research Therapy, 24, 597-602.

Scheibe, S., \& Blanchard-Fields, F. (2009). Effects of regulating emotions on cognitive performance: What is costly for young adults is not so costly for older adults. Psychology and Aging, 24, 217-223.

Sexton, K. A., Norton, P. J., Walker, J. R., \& Norton, G. R. (2003). Hierarchical model of generalized and specific vulnerabilities in anxiety. Cognitive Behaviour Therapy, 32, 8294.

Shmavonian, B. M., Miller, L. H., \& Cohen, S. I. (1968). Differences among age and sex groups 
in electrodermal conditioning. Psychophysiology, 5, 119-131.

Spielberger, C. D., Gorsuch, R. R., \& Luchene, R. E. (1970). The State-Trait Anxiety Inventory. Palo Alto, CA: Consulting Psychologists Press.

Starcevic, V., \& Berle, D. (2006). Cognitive specificity of anxiety disorders: A review of selected key constructs. Depression and Anxiety, 23, 51-61.

Starcevic, V., Berle, D., Fenech, P., Milicevic, D., Lamplugh, C., \& Hannan, A. (2009). Distinctiveness of perceived health in panic disorder and relation to panic disorder severity. Cognitive Therapy and Research, 33, 323-333.

Stein, P. K., Kleiger, R. E., \& Rottman, J. N. (1997). Differing effects of age on heart rate variability in men and women. The American Journal of Cardiology, 80, 302-305.

Steketee, G. S., Grayson, J. B., \& Foa, E. B. (1985). Obsessive-compulsive disorder: Differences between washers and checkers. Behavior Research and Therapy, 23, 197-201.

Tabachnick, B. G., and Fidell, L. S. (2007). Using Multivariate Statistics, 5th ed. Boston: Allyn and Bacon.

Taylor, S., \& Asmundson, G. J. G. (2004). Treating health anxiety: A cognitive-behavioral approach. NewYork: The Guilford Press.

Teachman, B. A., \& Gordon, T. (2009). Age differences in anxious responding: Older and calmer unless the trigger is physical. Psychology and Aging, 24, 703-714.

Tull, M. T., Rodman, S. A., \& Roemer, L. (2008). An examination of the fear of bodily sensations and hypervigilance as predictors of emotion regulation difficulties among individuals with a recent history of uncued panic attacks. Journal of Anxiety Disorders, 22, 750-760.

Tull, M. T., \& Roemer, L. (2007). Emotion regulation difficulties associated with the experience 
of uncued panic attacks: Evidence of experiential avoidance, emotional nonacceptance, and decreased emotional clarity. Behavior Therapy, 38, 378-391.

Tull, M. T., Stipelman, B. A., Salters-Pedneault, K., \& Gratz, K. L. (2009). An examination of recent non-clinical panic attacks, panic disorder, anxiety sensitivity, and emotion regulation difficulties in the prediction of generalized anxiety disorder in an analogue sample. Journal of Anxiety Disorders, 23, 275-282.

Uchino, B. N., Birmingham, W., \& Berg, C. A. (2010). Are older adults less or more physiologically reactive? A meta-analysis of age-related differences in cardiovascular reactivity to laboratory tasks. Journal of Gerontology: Psychological Sciences, 76B, 154162.

Urry, H. L., \& Gross, J. J. (2010). Emotion regulation in older age. Current Directions in Psychological Science, 19, 352-357.

Waller, E., \& Scheidt, C. E. (2004). Somatoform disorders as disorders of affect regulation: A study comparing the TAS-20 with non-self-report measures of alexithymia. Journal of Psychosomatic Research, 57, 239-247.

Ware, J. E., Kosinski, M., \& Keller, S. D. (1996). A 12-item short form health survey: Construction of scales and preliminary tests of reliability and validity. Medical Care, 34, $220-233$.

Ware, J. E., \& Sherbourne, C. D. (1992). The MOS 36-item short-form health survey (SF-36): Conceptual framework and item selection. Medical Care, 30, 473-483.

Watson, D., Clark, L. A., \& Tellegen, A. (1988). Development and validation of brief measures of positive and negative affect: The PANAS scales. Journal of Personality and Social Psychology, 54, 1063-1070. 
Weems, C. F., Costa, N. M., Watts, S. E., Taylor, L. K., \& Cannon, M. F. (2007). Cognitive errors, anxiety sensitivity, and anxiety control beliefs: Their unique and specific associations with childhood anxiety symptoms. Behavior Modification, 31, 174-201.

Wetherell, J. L., Petkus, A. J., McChesney, K., Stein, M. B., Judd, P. H., Rockwell, E., et al. (2009). Older adults are less accurate than younger adults are identifying symptoms of anxiety and depression. Journal of Nervous and Mental Disease, 197, 623-626.

Williams, P. G. (2004). The psychopathology of self-assessed health: A cognitive approach to health anxiety and hypochondriasis. Cognitive Therapy and Research, 28, 629-644.

Williams, L. E., Bargh, J. A., Nocera, C. C., \& Gray, J. R. (2009). The unconscious regulation of emotion: Nonconscious reappraisal goals modulate emotional reactivity. Emotion, 9, 847854.

Wisocki, P. (1994). The experience of worry among the elderly. In: G. Davey \& F. Tallis (Eds.), Worrying: Perspectives on Theory, Assessment, and Treatment. New York: Wiley.

Wolitzky-Taylor, K. B., Castriotta, N., Lenze, E. J., Stanley, M. A., \& Craske, M. G. (2010). Anxiety disorders in older adults: A comprehensive review. Depression and Anxiety, 27, 190-211.

Wolpe, J., \& Lang, P. J. A. (1964). A Fear Survey Schedule for use in behavior therapy. Behavior Research and Therapy, 2, 27-30.

Zebb, B. J., \& Moore, M. C. (1999). Another look at the psychometric properties of the Anxiety Control Questionnaire. Behaviour Research and Therapy, 37, 1091-1103.

Zvolensky, M. J., \& Forsyth, J. P. (2002). Anxiety sensitivity dimensions in the prediction of body vigilance and emotional avoidance. Cognitive Therapy and Research, 26, 449-460. 


\title{
Appendix A
}

Short Health Anxiety Inventory

\section{SHORT MONTH}

\section{HAI}

Ass / Wk / Sess:

\begin{abstract}
Each question is this section consists of a group of four statements. Please read each group of statements carefully and then select the one which best describes your feelings, OVER THE PAST SIX MONTHS. Identify the statement by ringing the letter next to it ie. if you think that statement (a) is correct, ring statement (a); it may be that more than one statement applies, in which case, please ring any that are applicable.
\end{abstract}

1. a. I do not worry about my health

b. I occasionally worry about my health.

c. I spend much of my time worrying about my health.

d. I spend most of my time worrying about my health.

2.

I notice aches/pains less than most other people (of my age).

b. I notice aches/pains as much as most other people (of my age).

c. I notice aches/pains more than most other people (of my age).

d. I am aware of aches/pains in my body all the time.

3. a. As a rule I am not aware of bodily sensations or changes.

Sometimes I am aware of bodily sensations or changes.

I am often aware of bodily sensations or changes.

I am constantly aware of bodily sensations or changes.

4. a. Resisting thoughts of illness is never a problem

Most of the time I can resist thoughts of illness.

I try to resist thoughts of illness but am often unable to do so.

Thoughts of illness are so strong that I no longer even try to resist them.

5. a. As a rule I am not afraid that I have a serious illness.

I am sometimes afraid that I have a serious illness.

I am often afraid that I have a serious illness.

d. I am always afraid that I have a serious illness.

6.

I do not have images (mental pictures) of myself being ill.

b. I occasionally have images of myself being ill.

c. I frequently have images of myself being ill.

d. I constantly have images of myself being ill.

7. a. I do not have any difficulty taking my mind off thoughts about my health.

b. I sometimes have any difficulty taking my mind off thoughts about my health.

c. I often have any difficulty taking my mind off thoughts about my health.

d. Nothing can tame my mind off thoughts about my health.

8. a. I am lastingly relieved if my doctor tells me there is nothing wrong.

b. I am initially relieved but the worries sometimes return later.

c. I am initially relieved but the worries always return later.

d. I am not relieved if my doctor tells me there is nothing wrong.

9. a. If I hear about an illness I never think I have it myself.

If I hear about an illness I sometimes think I have it myself.

If I hear about an illness I often think I have it myself.

If I hear about an illness I always think I have it myself.

10. a. If I have a bodily sensation or change I rarely wonder what it means. If I have a bodily sensation or change I often wonder what it means.

If I have a bodily sensation or change I always wonder what it means.

If I have a bodily sensation or change I must know what it means. 
11. a. I usually feel at very low risk for developing a serious illness.

b. I usually feel at fairly low risk for developing a serious illness.

c. I usually feel at moderate risk for developing a serious illness.

d. I usually feel at high risk for developing a serious illness.

12. a. I never think I have a serious illness.

b. I sometimes think I have a serious illness.

c. I often think I have a serious illness.

d. I usually think that I am seriously ill.

13. a. If I notice an unexplained bodily sensation I never do anything to try to get rid of it.

b. If I notice an unexplained bodily sensation I sometimes try to get rid of it.

c. If I notice an unexplained bodily sensation I often try to get rid of it.

d. If I notice an unexplained bodily sensation I always try to get rid of it.

14. a. My family/friends would say I do not worry enough about my health.

b. My family/friends would say I have a normal attitude to my health.

c. My family/friends would say I worry too much about my health.

d. My family/friends would say I am a hypochondriac.

For the following questions, please think about what it might be like if you had a serious illness of a type which particularly concerns you (such as heart disease, cancer, multiple sclerosis and so on). Obviously you cannot know for definite what it would be like; please give your best estimate of what you think might happen, basing your estimate on what you know about yourself and serious illness in general.

15. a. If I had a serious illness I would still be able to enjoy things in my life quite a lot.

b. If I had a serious illness I would still be able to enjoy things in my life a little.

c. If I had a serious illness I would be almost completely unable to enjoy things in my life.

d. If I had a serious illness I would be completely unable to enjoy life at all.

16. a. If I developed a serious illness there is a good chance that modern medicine would be able to cure me.

b. If I developed a serious illness there is a moderate chance that modern medicine would be able to cure me.

c. If I developed a serious illness there is a very small chance that modern medicine would be able to cure me.

d. If I developed a serious illness there is no chance that modern medicine would be able to cure me.

17. a. A serious illness would ruin some aspects of my life.

b. A serious illness would ruin many aspects of my life.

c. A serious illness would ruin almost every aspect of my life.

d. A serious illness would ruin every aspect of my life.

18. a. If I had a serious illness I would not feel that I had lost my dignity.

b. If I had a serious illness I would feel that I had lost a little of my dignity.

c. If I had a serious illness I would feel that I had lost quite a lot of my dignity.

d. If I had a serious illness I would feel that I had totally lost my dignity. 


\section{Appendix B}

Demographics Questionnaire

Please answer the following questions.

Age:

Gender: Please check one. Male

$\square$ Female

Years of Education: (high school $=12$ years)

Marital Status: Please check one.

$\square$ Single $\square$ Married $\square$ Separated $\square$ Divorced $\square$ Widowed

If married/separated/divorced/widowed, please write in the number of years married on the line:

Ethnicity: (race) Please check all that apply.

$\square$ Caucasian (White)

$\square$ African American (Black)

$\square$ Asian American

$\square$ Hispanic

$\square$ Pacific Islander

$\square$ Native American (American Indian/Alaskan Native)

$\square$ Other:

What is your current job or occupation status? Please check one.

$\square$ Working full time

$\square$ Working part time

$\square$ Homemaker

$\square$ Student

$\square$ Looking for work, unemployed

$\square$ Retired

$\square$ Disabled - unable to work 


\section{Have you ever had any of the following conditions? Circle all that apply.}

\begin{tabular}{lll} 
Anemia & Emphysema & Kidney or Gallbladder stones \\
Angina & Epilepsy/Seizures & Lupus \\
Anxiety & Fibromyalgia & Macular Degeneration \\
Arthritis & Gastroesophageal reflux & Mononucleosis \\
Asthma/ Bronchitis & \multicolumn{1}{c}{ disorder (GERD) } & Multiple Sclerosis \\
Autoimmune disease & Genetic Condition & Neuropathy \\
Bleeding disorder & Gout & Osteoporosis \\
Blood clots & Glaucoma & Parkinson's Disease \\
Cancer & Headaches & Pneumonia \\
Cardiac Arrhythmia & Hearing loss & Polio \\
Cataracts & Heart Attack & Rheumatic Fever \\
Coronary Artery Disease & Hepatitis & Scarlet Fever \\
Crohn's Disease/Colitis & High cholesterol & Sexually Transmitted Disease \\
Deep Venous Thrombosis & HIV/AIDS & Sinus/Upper respiratory infection \\
Depression & Hormonal problems/imbalances & Stomach ulcers \\
Diabetes & High blood pressure & Stroke \\
Diverticulitis/Diverticulosis & Irritable Bowel Syndrome & Thyroid problems \\
Other: & & \\
\hline
\end{tabular}


Appendix C

\section{SF-12: Your Health and Well-Being}

This survey asks for your views about your health. This information will help keep track of how you feel and how well you are able to do your usual activities.

For each of the following questions, please mark an $\mathrm{X}$ in the one box that best describes your answer.

1. In general, would you say your health is:

Excellent

Very Good

Good

Fair

Poor
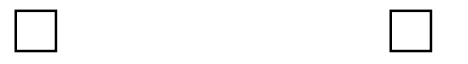

2. The following questions are about activities you might do during a typical day. Does your health now limit you in these activities? If yes, how much?

\begin{tabular}{|c|c|c|c|}
\hline Moderate activities, such as moving a table, & $\begin{array}{l}\text { Yes, } \\
\text { limited }\end{array}$ & $\begin{array}{l}\text { Yes, } \\
\text { limited }\end{array}$ & $\begin{array}{l}\text { No, not } \\
\text { limited }\end{array}$ \\
\hline cleaner, bowling, or & a lot & a little & at all \\
\hline ay & $\ldots \square$ & $\square$ & $\square$ \\
\hline
\end{tabular}

Climbing several flights of stairs. 
3. During the past 4 weeks, how much of the time have you had any of the following problems with your work or other regular daily activities as a result of your physical health?

$\begin{array}{lcc}\begin{array}{l}\text { All of } \\ \text { the time }\end{array} & \begin{array}{c}\text { Most of } \\ \text { the time }\end{array} \\ \text { would like............................. } \square & \square\end{array}$

Were limited in the kind of

work or other activities

4. During the past 4 weeks, how much of the time have you had any of the following problems with your work or other regular daily activities as a result of any emotional problems (such as feeling depressed or anxious)?

\begin{tabular}{|c|c|c|c|c|c|}
\hline $\mathrm{cc}$ & $\begin{array}{l}\text { All of } \\
\text { the time }\end{array}$ & $\begin{array}{l}\text { Most of } \\
\text { the time }\end{array}$ & $\begin{array}{l}\text { Some of } \\
\text { the time }\end{array}$ & $\begin{array}{c}\text { A little } \\
\text { of the time }\end{array}$ & $\begin{array}{l}\text { None } \\
\text { the time }\end{array}$ \\
\hline ike & & & $\square$ & $\square$ & \\
\hline
\end{tabular}

Did work or other activities

less carefully than usual...............

5. During the past 4 weeks, how much did pain interfere with your normal work (including both work outside the home and housework)?

Not at all

A little bit

Moderately

Quite a bit

Extremely 
6. These questions are about how you feel and how things have been with you during the past 4 weeks. For each question, please give the one answer that comes closest to the way you have been feeling. How much of the time during the past $\underline{4}$ weeks...

$\begin{array}{ccc}\text { All of } & \text { Most of } & \text { Some of A little None } \\ \text { the time the time the time of the time the time }\end{array}$

Have you felt calm and peaceful?

......

Did you have a lot of energy?

Have you felt down hearted

and depressed?

7. During the past 4 weeks, how much of the time has your physical health or emotional problems interfered with your social activities (like visiting friends, relatives, etc.)?

$\begin{array}{cccc}\text { All of the } & \text { Most of the Some of the A little of } \\ \text { time } & \text { time } & \text { time } & \text { the time }\end{array}$




\section{Appendix D \\ Anxiety Sensitivity Index}

Please rate each item by selecting one of the five answers for each question. Please answer each statement by circling the number that best applies to you.

Very A little Some Much $\begin{aligned} & \text { Very } \\ & \text { Little }\end{aligned}$
Much

1. It is important not to appear nervous.

2. When I cannot keep my mind on a task, I worry

$\begin{array}{lllll}0 & 1 & 2 & 3 & 4 \\ 0 & 1 & 2 & 3 & 4\end{array}$

that I might be going crazy.

3. It scares me when I feel shaky.

4. It scares me when I feel faint.

5. It is important to me to stay in control of my

$\begin{array}{lllll}0 & 1 & 2 & 3 & 4\end{array}$
emotions.

6. It scares me when I my heart beat rapidly.

7. It embarrasses me when my stomach growls.

8. It scares me when I am nauseous (sick stomach).

9. When I notice my heart beating rapidly, I worry

$\begin{array}{lllll}0 & 1 & 2 & 3 & 4\end{array}$

that I might be having a heart attack.

10. It scares me when I become short of breath.

11. When my stomach is upset, I worry that I might be seriously ill.

12. It scares me when I am unable to keep my mind on a $\begin{array}{llllll}0 & 1 & 2 & 3 & 4\end{array}$ task.

13. Other people notice when I feel shaky.

14. Unusual body sensations scare me.

15. When I am nervous, I worry that I might be

$\begin{array}{lllll}0 & 1 & 2 & 3 & 4 \\ 0 & 1 & 2 & 3 & 4 \\ 0 & 1 & 2 & 3 & 4\end{array}$
mentally ill.

16. It scares me when I am nervous.

$\begin{array}{lllll}0 & 1 & 2 & 3 & 4\end{array}$




\section{Appendix E \\ Intolerance of Uncertainty Scale}

You will find below a series of statements which describe how people may react to the uncertainties of life. Please use the scale below to describe to what extent each item is characteristic of you. Please circle a number (1 to 5) that describes you best.

$$
\begin{gathered}
\text { Not at all } \\
\text { characteristic } \\
\text { of me }
\end{gathered}
$$

$$
\begin{aligned}
& \text { Somewhat } \\
& \text { characteristic } \\
& \text { of me }
\end{aligned}
$$

$$
\begin{gathered}
\text { Entirely } \\
\text { characteristic } \\
\text { of me }
\end{gathered}
$$

1. Uncertainty stops me from having a firm opinion

2. Being uncertain means that a person is disorganized

3. Uncertainty makes life intolerable.

4. It's unfair not having any guarantees in life.

5. My mind can't be relaxed if I don't know what will happen tomorrow.

6. Uncertainty makes me uneasy, anxious, or stressed.

7. Unforeseen events upset me greatly.

8. It frustrates me not having all the information I need.

9. Uncertainty keeps me from living a full life.

10. One should always look ahead so as to avoid surprises.

11. A small unforeseen event can spoil everything, even with the best of planning.

12. When it's time to act, uncertainty paralyses me.

13. Being uncertain means that I am not first rate.

14. When I am uncertain, I can't go forward.

15. When I am uncertain I can't function very well.

16. Unlike me, others always seem to know where they are going with their lives 


\author{
Not at all \\ characteristic \\ of me
}

\author{
Somewhat \\ characteristic \\ of me
}

\author{
Entirely \\ characteristic \\ of me
}

17. Uncertainty makes me vulnerable, unhappy, or sad.

18. I always want to know what the future has in store for me.

19. I can't stand being taken by surprise.

20. The smallest doubt can stop me from acting.

21. I should be able to organize everything in advance.

22. Being uncertain means that I lack confidence.

23. I think it's unfair that other people seem sure about their future.

24. Uncertainty keeps me from sleeping soundly.

25. I must get away from all uncertain situations.

26. The ambiguities in life stress me

27. I can't stand being undecided about my future 


\author{
Appendix F \\ Emotion Regulation Questionnaire (ERQ) \\ Gross \& John \\ $9 / 03$
}

\title{
Instructions and Items
}

We would like to ask you some questions about your emotional life, in particular, how you control (that is, regulate and manage) your emotions. The questions below involve two distinct aspects of your emotional life. One is your emotional experience, or what you feel like inside. The other is your emotional expression, or how you show your emotions in the way you talk, gesture, or behave. Although some of the following questions may seem similar to one another, they differ in important ways. For each item, please answer using the following scale:

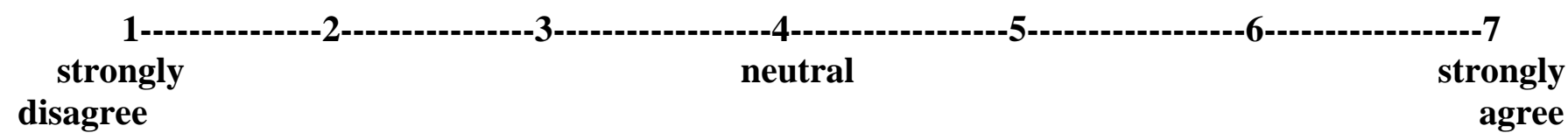

1. W__ When I want to feel more positive emotion (such as joy or amusement), I change what I'm thinking about.

2. ___ I keep my emotions to myself.

3. When I want to feel less negative emotion (such as sadness or anger), I change what I'm thinking about.

4. When I am feeling positive emotions, I am careful not to express them.

5. When I'm faced with a stressful situation, I make myself think about it in a way that helps me stay calm.

6.___ I control my emotions by not expressing them.

7. When I want to feel more positive emotion, I change the way I'm thinking about the situation.

8. I I control my emotions by changing the way I think about the situation I'm in.

9. W__ When I am feeling negative emotions, I make sure not to express them.

10. When I want to feel less negative emotion, I change the way I'm thinking about the situation. 


\section{Appendix G}

Anxiety Control Questionnaire

Listed below are a number of statements describing a set of beliefs. Please read each statement carefully and, on the 0-5 scale given, indicate how much you think each statement is typical of you.

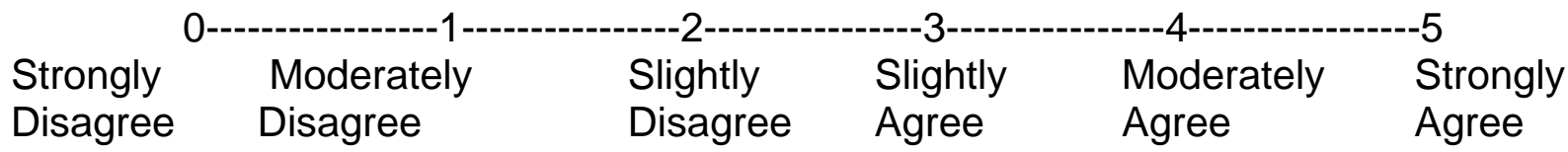

1. I am usually able to avoid threat quite easily.

2. How well I cope with difficult situations depends on whether I have outside help.

3. When I am put under stress, I am likely to lose control.

4. I can usually stop my anxiety from showing.

5. When I am frightened by something, there is generally nothing I can do.

6. My emotions seem to have a life of their own.

7. There is little I can do to influence people's judgments of me.

8. Whether I can successfully escape a frightening situation is always a matter of chance with me.

9. I often shake uncontrollably.

10. I can usually put worrisome thoughts out of my mind easily.

11. When I am in a stressful situation, I am able to stop myself from breathing too hard.

12. I can usually influence the degree to which a situation is potentially threatening to me.

13. I am able to control my level of anxiety.

14. There is little I can do to change frightening events.

15. The extent to which a difficult situation resolves itself has nothing to do with my actions. 


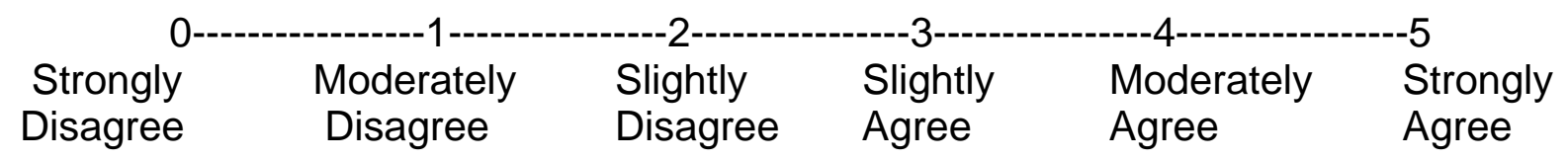

16. If something is going to hurt me, it will happen no matter what I do.

17. I can usually relax when I want.

18. When I am under stress, I am not always sure how I will react.

19. I can usually make sure people like me if I work at it.

20. Most events that make me anxious are outside my control.

21. I always know exactly how I will react to difficult situations.

22. I am unconcerned if I become anxious in a difficult situation, because I am confident in my ability to cope with my symptoms.

23. What people think of me is largely outside my control.

24. I usually find it hard to deal with difficult problems.

25. When I hear that someone has a serious illness, I worry that I am next.

26. When I am anxious, I find it difficult to focus on anything other than my anxiety.

27. I am able to cope as effectively with unexpected anxiety as I am with anxiety that I expect to occur.

28. I sometimes think, "Why even bother to try to cope with my anxiety when nothing I do seems to affect how frequently or intensely I experience it?".

29. I often have the ability to get along with "difficult" people.

30. I will avoid conflict due to my inability to successfully resolve it. 
Table 1. Means and standard deviations of predictor and outcome variables by age group.

\begin{tabular}{|c|c|c|c|c|c|}
\hline & & \multicolumn{2}{|c|}{ Older Adults } & \multicolumn{2}{|c|}{ Young Adults } \\
\hline & & $M$ & $S D$ & $M$ & $S D$ \\
\hline SHAI & & 11.23 & 6.97 & 14.68 & 6.97 \\
\hline & IL & 9.10 & 5.68 & 11.59 & 5.93 \\
\hline & $\mathrm{NC}$ & 2.12 & 1.98 & 3.06 & 2.03 \\
\hline ASI & & 17.24 & 10.84 & 20.82 & 11.04 \\
\hline IUS & & 52.15 & 18.87 & 63.55 & 22.06 \\
\hline ACQ & & 98.65 & 21.32 & 89.69 & 19.18 \\
\hline & Reactions & 47.76 & 11.58 & 40.88 & 10.49 \\
\hline & Events & 50.90 & 11.99 & 48.81 & 10.81 \\
\hline \multicolumn{6}{|l|}{ ERQ } \\
\hline & Reappraisal & 30.86 & 5.82 & 28.57 & 5.86 \\
\hline & Suppression & 15.37 & 5.56 & 14.94 & 4.61 \\
\hline \multicolumn{6}{|l|}{ SF-12 } \\
\hline & PCS & 45.34 & 10.85 & 53.42 & 7.64 \\
\hline & MCS & 51.21 & 9.54 & 42.44 & 10.64 \\
\hline
\end{tabular}

Note: $\mathrm{SHAI}=$ Short Health Anxiety Inventory; $\mathrm{IL}=$ Illness Likelihood; $\mathrm{NC}=$ Negative Consequences; ASI = Anxiety Sensitivity Index; IUS = Intolerance of Uncertainty Scale; ACQ = Anxiety Control Questionnaire; ERQ = Emotion Regulation Questionnaire; SF-12 = Short Form Health Survey-12 Item; PCS = Physical Component Summary; MCS = Mental Component 
Summary. Significant mean differences between age groups were observed for all variables except for the Events subscale of the ACQ and Suppression subscale of the ERQ. All mean differences were significant at the .01 level except for the ASI, which was significant at the .05 level. 
Table 2. Correlations among outcome and predictor variables for older and younger adults.

\begin{tabular}{|c|c|c|c|c|c|c|c|c|c|c|c|}
\hline & SHAI & SHAI IL & SHAI NC & ASI & ACQ & ACQ & ACQ & Reapp & Supp & IUS & PCS \\
\hline & & & & & & Reactions & Events & & & & \\
\hline SHAI IL & $.97 *$ & - & & & & & & & & & \\
\hline SHAI NC & $.66 *$ & $.44 *$ & - & & & & & & & & \\
\hline ASI & $.54 *$ & $.53 *$ & $.34 *$ & - & & & & & & & \\
\hline $\mathrm{ACQ}$ & $-.47 *$ & $-.43 *$ & $-.39 *$ & $-.54 *$ & - & & & & & & \\
\hline ACQ Reactions & $-.49 *$ & $-.44 *$ & $-.41 *$ & $-.46 *$ & $.90 *$ & - & & & & & \\
\hline ACQ Events & $-.36 *$ & $-.32 *$ & $-.30 *$ & $-.51 *$ & $.90 *$ & $.62 *$ & - & & & & \\
\hline Reappraisal & $-.19 *$ & $-.15 * *$ & $-.22 *$ & $-.28 *$ & $.51 *$ & $.48 *$ & $.43 *$ & - & & & \\
\hline Suppression & .06 & .06 & .04 & $.19 *$ & -.07 & .05 & $-.18 * *$ & .08 & - & & \\
\hline IUS & $.57 *$ & $.50 *$ & $.52 *$ & $.48 *$ & $-.68 *$ & $-.68 *$ & $-.55 *$ & $-.26 *$ & .08 & - & \\
\hline PCS & -.10 & $-.14 * *$ & .08 & $-.16 * *$ & .12 & .06 & $.17 * *$ & .06 & .01 & .05 & - \\
\hline MCS & $-.57 *$ & $-.53 *$ & $-.41 *$ & $-.33 *$ & $-.55 *$ & $.61 *$ & $.39 *$ & $.33 *$ & .01 & $-.60 *$ & $-.16 * *$ \\
\hline
\end{tabular}


Table 3. Correlations among outcome and predictor variables for older adults.

\begin{tabular}{|c|c|c|c|c|c|c|c|c|c|c|c|}
\hline & & & & & & ACQ & ACQ & & & & \\
\hline & SHAI & SHAI IL & SHAI NC & ASI & ACQ & Reactions & Events & Reapp & Supp & IUS & PCS \\
\hline SHAI IL & $.97 *$ & - & & & & & & & & & \\
\hline SHAI NC & $.72 *$ & $.53 *$ & - & & & & & & & & \\
\hline ASI & $.63 *$ & $.59 *$ & $.48 *$ & - & & & & & & & \\
\hline ACQ & $-.49 *$ & $-.46 *$ & $-.38 *$ & $-.51 *$ & - & & & & & & \\
\hline ACQ Reactions & $-.56 *$ & $-.53 *$ & $-.45 *$ & $-.54 *$ & $.90 *$ & - & & & & & \\
\hline ACQ Events & $-.32 *$ & $-.30 *$ & $-.25 *$ & $-.38 *$ & $.91 *$ & $.64 *$ & - & & & & \\
\hline Reappraisal & -.06 & -.03 & -.14 & $-.26 * *$ & $.47 *$ & $.40 *$ & $.45 *$ & - & & & \\
\hline Suppression & .03 & .01 & .08 & .14 & -.13 & -.01 & -.22 & -.01 & - & & \\
\hline IUS & $.58 *$ & $.52 *$ & $.51 *$ & $.47 *$ & $-.67 *$ & $-.73 *$ & $-.48 *$ & -.17 & .04 & - & \\
\hline PCS & $-.41 *$ & $-.45 *$ & -.14 & $-.26 * *$ & $.28 * *$ & $.24 * *$ & $.26 * *$ & .13 & .01 & -.13 & - \\
\hline MCS & $-.62 *$ & $-.59 *$ & $-.47 *$ & $-.38 *$ & $.58 *$ & $.59 *$ & $.47 *$ & $.28 *$ & .01 & $-.62 *$ & .21 \\
\hline
\end{tabular}


Table 4. Correlations among outcome and predictor variables for younger adults.

\begin{tabular}{|c|c|c|c|c|c|c|c|c|c|c|c|}
\hline & & & & & & ACQ & ACQ & & & & \\
\hline & SHAI & SHAI IL & SHAI NC & ASI & ACQ & Reactions & Events & Reapp & Supp & IUS & PCS \\
\hline SHAI IL & $.96 *$ & - & & & & & & & & & \\
\hline SHAI NC & $.58 *$ & $.34 *$ & - & & & & & & & & \\
\hline ASI & $.45 *$ & $.46 *$ & $.20 * *$ & - & & & & & & & \\
\hline ACQ & $-.41 *$ & $-.36 *$ & $-.34 *$ & $-.53 *$ & - & & & & & & \\
\hline ACQ Reactions & $-.37 *$ & $-.32 *$ & $-.30 *$ & $-.36 *$ & $.90 *$ & - & & & & & \\
\hline ACQ Events & $-.37 *$ & $-.32 *$ & $-.32 *$ & $-.60 *$ & $.90 *$ & $.62 *$ & - & & & & \\
\hline Reappraisal & $-.21 * *$ & -.18 & $-.21 * *$ & $-.26 *$ & $.50 *$ & $.50 *$ & $.41 *$ & - & & & \\
\hline Suppression & .11 & .12 & .02 & $.26 *$ & -.03 & .09 & -.15 & .14 & - & & \\
\hline IUS & $.52 *$ & $.44 *$ & $.48 *$ & $.46 *$ & $-.67 *$ & $-.61 *$ & $-.60 *$ & $-.25 *$ & .13 & - & \\
\hline PCS & -.02 & -.06 & .12 & $-.24 * *$ & $.19 * *$ & .16 & $.18 * *$ & $.18 * *$ & .02 & .01 & - \\
\hline MCS & $-.47 *$ & $-.45 *$ & $-.29 *$ & $-.24 *$ & $.48 *$ & $.54 *$ & $.34 *$ & $.29 *$ & -.05 & $-.52 *$ & $-.20 * *$ \\
\hline
\end{tabular}


Table 5. Hierarchical regression analysis with SHAI scores as the outcome variable.

\begin{tabular}{|c|c|c|c|c|}
\hline & & $\beta$ & $p$ & $R^{2}$ \\
\hline \multirow[t]{3}{*}{ Step 1} & & & & 0.35 \\
\hline & PCS & -0.18 & 0.01 & \\
\hline & MCS & -0.60 & 0.01 & \\
\hline \multirow[t]{7}{*}{ Step 2} & & & & 0.36 \\
\hline & PCS & -0.21 & 0.01 & \\
\hline & MCS & -0.56 & 0.01 & \\
\hline & Age & 0.10 & 0.16 & \\
\hline & Gender & 0.01 & 0.94 & \\
\hline & Education & -0.01 & 0.94 & \\
\hline & Income & -0.01 & 0.93 & \\
\hline \multirow[t]{9}{*}{ Step 3} & & & & 0.51 \\
\hline & PCS & -0.14 & 0.02 & \\
\hline & MCS & -0.37 & 0.01 & \\
\hline & Age & 0.08 & 0.20 & \\
\hline & Gender & -0.02 & 0.68 & \\
\hline & Education & 0.01 & 0.92 & \\
\hline & Income & -0.02 & 0.69 & \\
\hline & ASI & 0.35 & 0.01 & \\
\hline & IUS & 0.26 & 0.01 & \\
\hline
\end{tabular}




$\begin{array}{lll}\text { ACQ } & 0.10 & 0.27 \\ \text { Reappraisal } & 0.08 & 0.21 \\ \text { Suppression } & -0.02 & 0.71\end{array}$

Step 4

\begin{tabular}{|c|c|c|}
\hline PCS & -0.14 & 0.03 \\
\hline MCS & -0.35 & 0.01 \\
\hline Age & 0.10 & 0.14 \\
\hline Gender & -0.03 & 0.60 \\
\hline Education & 0.03 & 0.57 \\
\hline Income & -0.03 & 0.66 \\
\hline ASI & 0.48 & 0.01 \\
\hline IUS & 0.22 & 0.11 \\
\hline $\mathrm{ACQ}$ & 0.03 & 0.80 \\
\hline Reappraisal & 0.21 & 0.03 \\
\hline Suppression & -0.02 & 0.74 \\
\hline ASI x Age & -0.16 & 0.11 \\
\hline IUS x Age & 0.05 & 0.71 \\
\hline ACQ x Age & 0.07 & 0.56 \\
\hline Reapp x Age & -0.17 & 0.08 \\
\hline Supp x Age & 0.02 & 0.79 \\
\hline
\end{tabular}

Note: All scale scores are centered. ASI = Anxiety Sensitivity Index; IUS = Intolerance of Uncertainty Scale; ACQ = Anxiety Control Questionnaire. 
Figure 1.

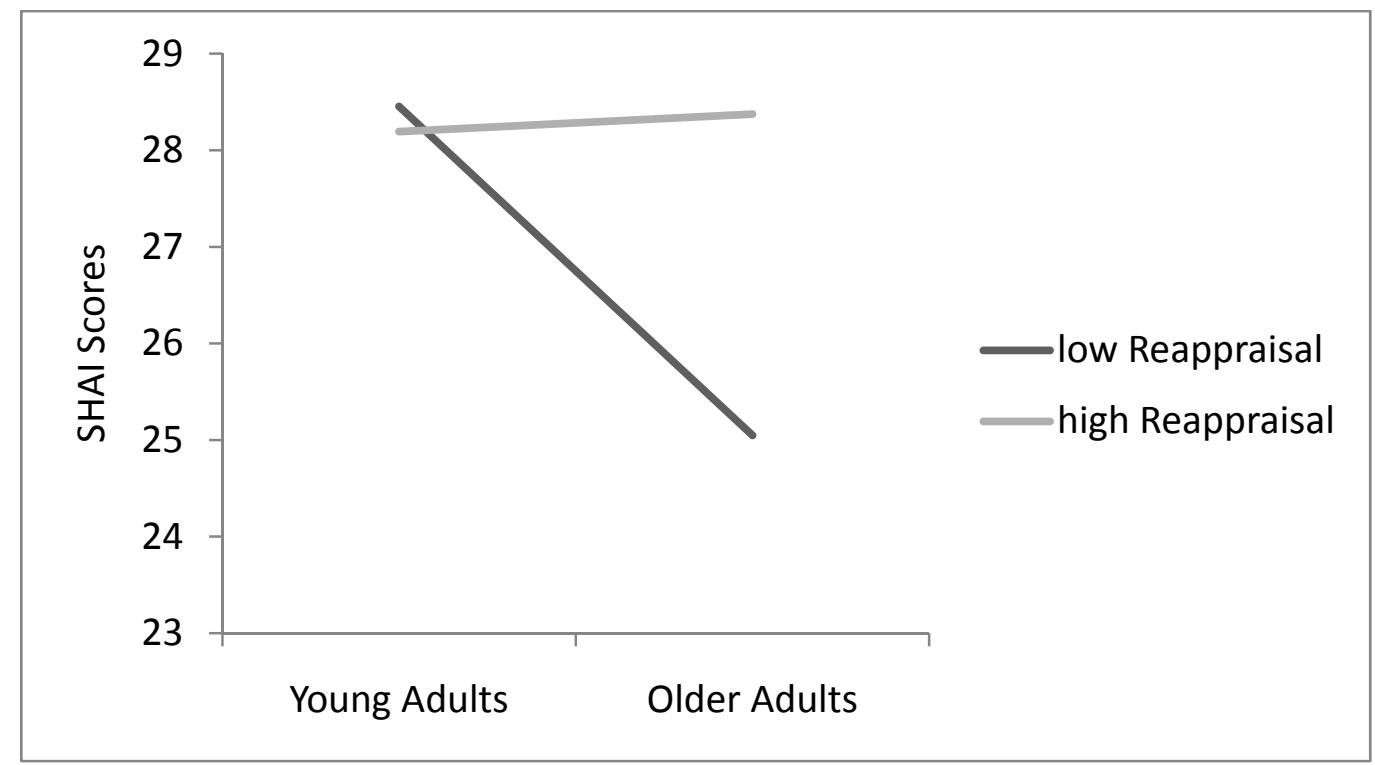

Figure 1. Interaction of age group and reappraisal subscale scores in predicting Short Health Anxiety Inventory (SHAI) scores. 
Figure 2.

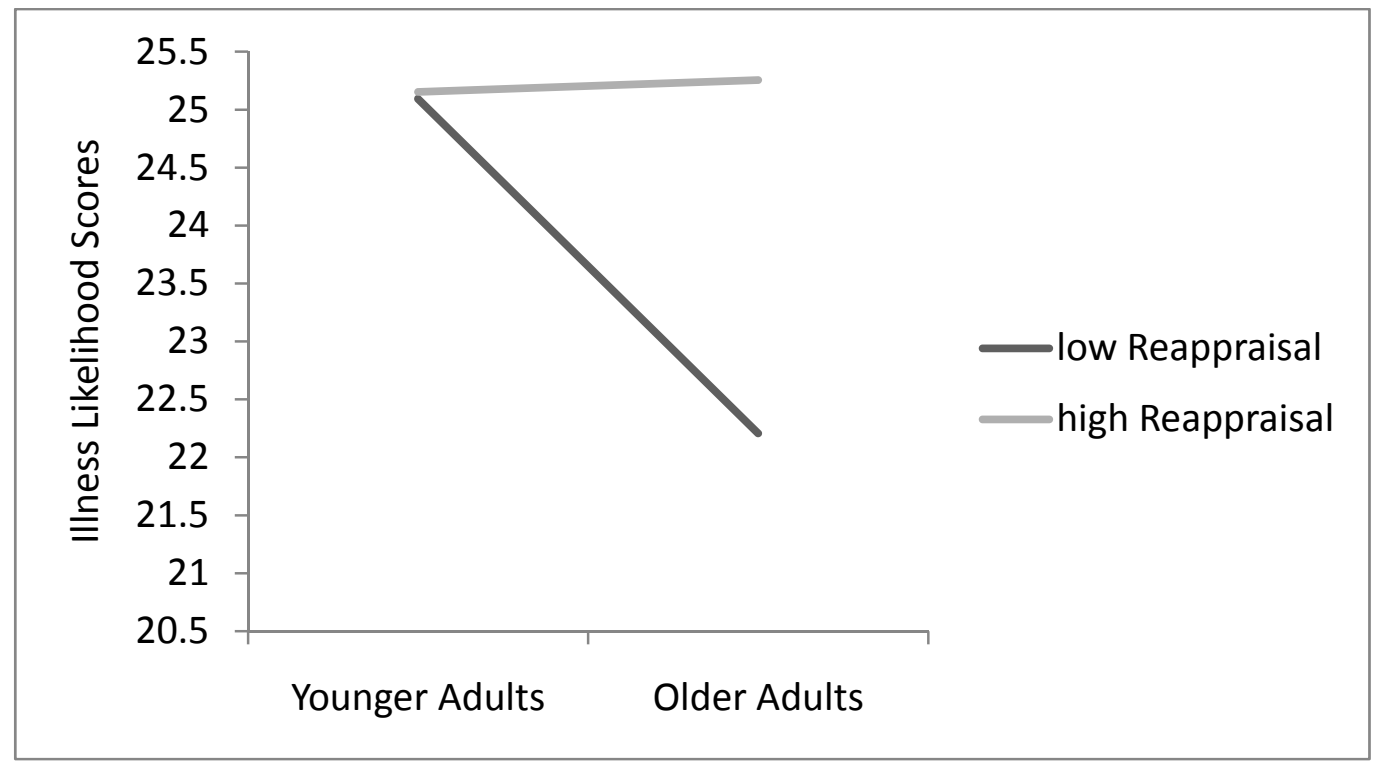

Figure 2. Interaction of age group and reappraisal subscale scores in predicting illness likelihood scores of the Short Health Anxiety Inventory (SHAI). 
Figure 3.

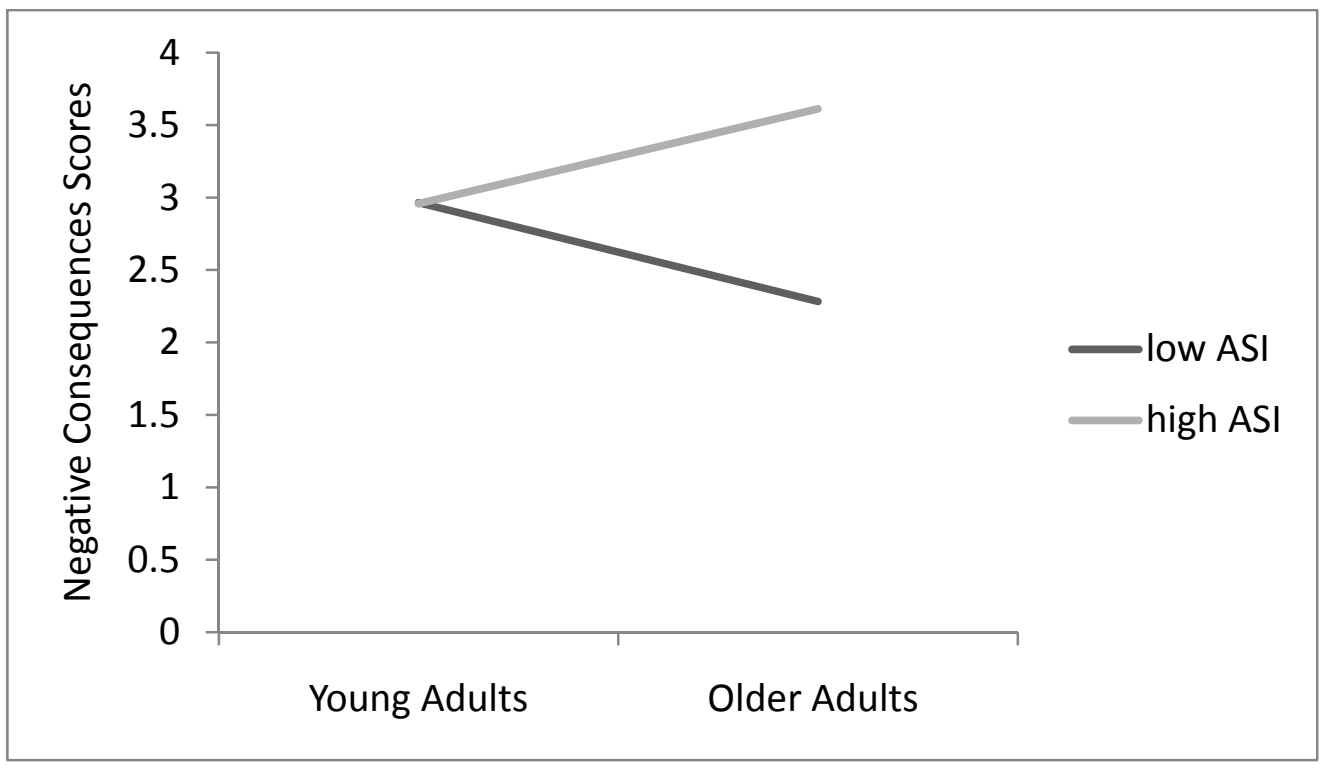

Figure 3. Interaction of age group with anxiety sensitivity (ASI) scores in predicting negative consequences scores of the Short Health Anxiety Inventory (SHAI). 
Figure 4.

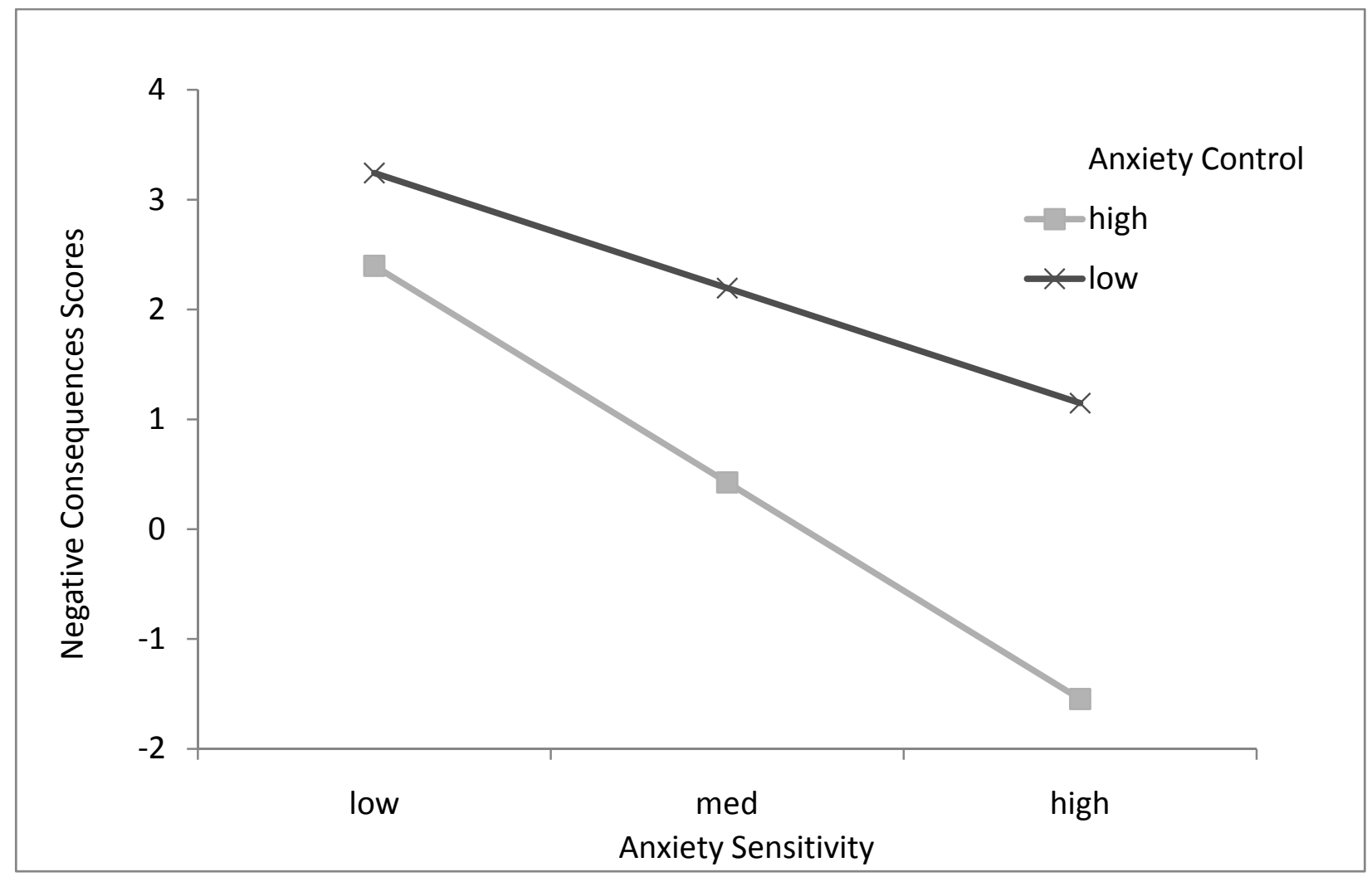

Figure 4. Interaction of anxiety sensitivity and anxiety control in predicting negative consequences scores of the Short Health Anxiety Inventory (SHAI) for older adults. 
Figure 5.

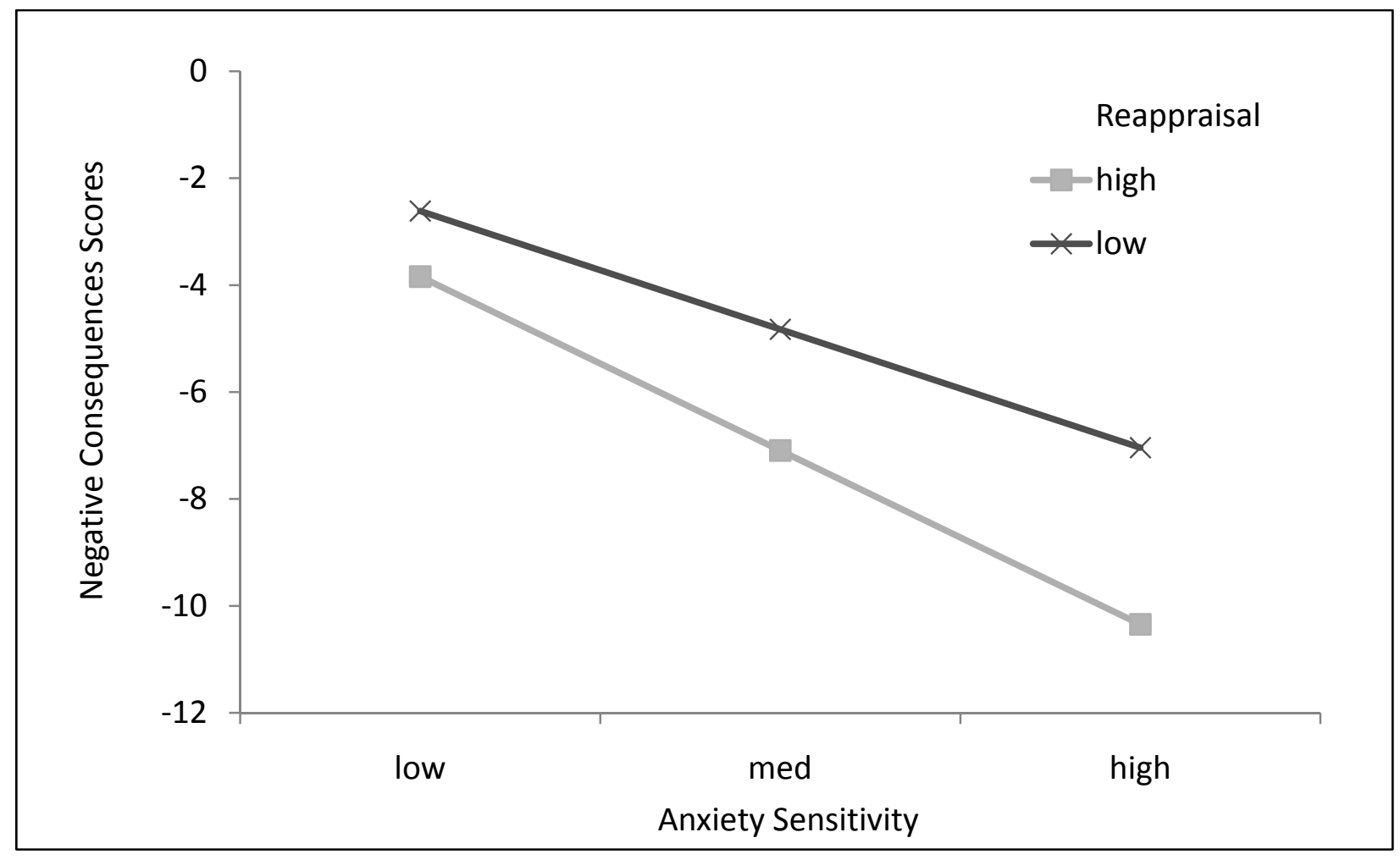

Figure 5. Interaction between anxiety sensitivity and reappraisal in predicting negative consequences scores of the Short Health Anxiety Inventory (SHAI) for younger adults. 
Figure 6.

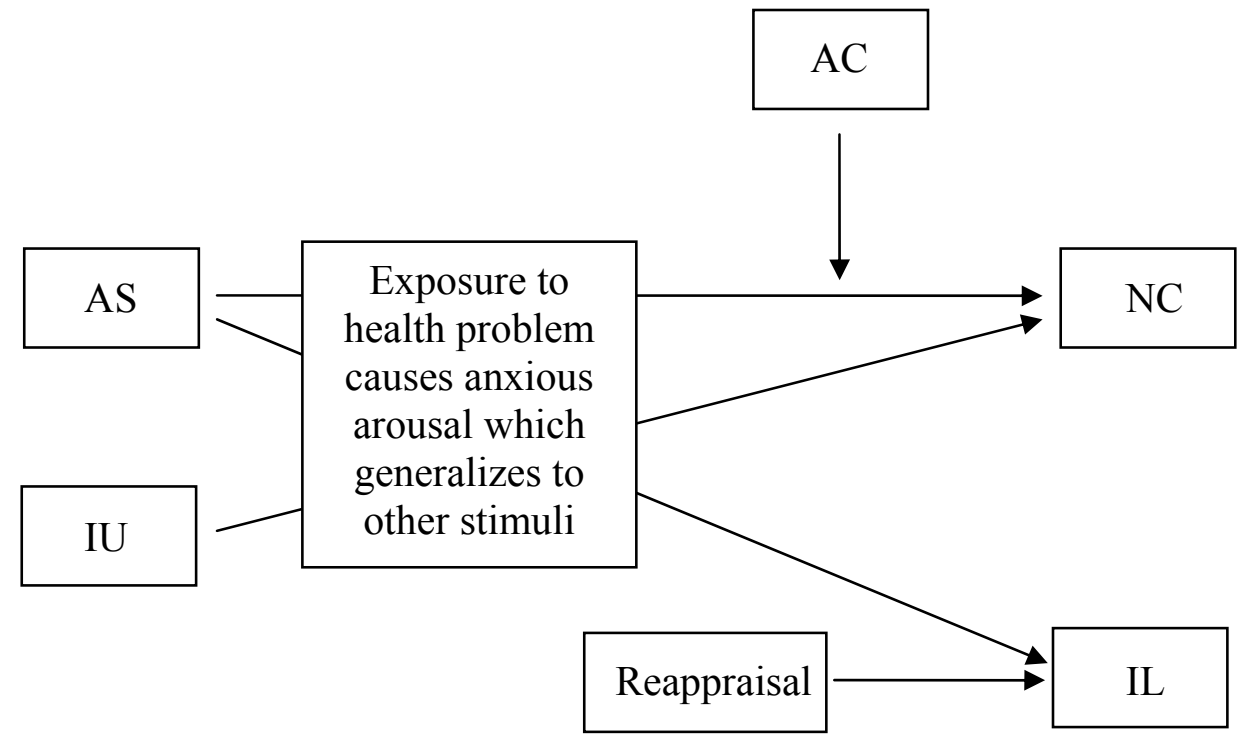

Figure 6. Proposed conceptual model accounting for health anxiety in older adults. For older adults, anxiety sensitivity and intolerance of uncertainty are predisposing characteristics. Then, individuals are subjected to a serious health problem (in self, others, or the news), which causes anxiety-related symptoms. Anxious responding may then generalize to other illness-related stimuli. When faced with these stimuli, older individuals consider perceived likelihood (IL) and negative consequences (NC) or costs of an illness. These anxious thought patterns are attenuated by coping factors, such as perceived control over anxiety (AC) when considering $\mathrm{NC}$, or reappraisal skills when considering IL. The availability of rescue factors (e.g., cures) also impinges on the model, though this factor was not explored in the present study and is not presented above. 
Figure 7.

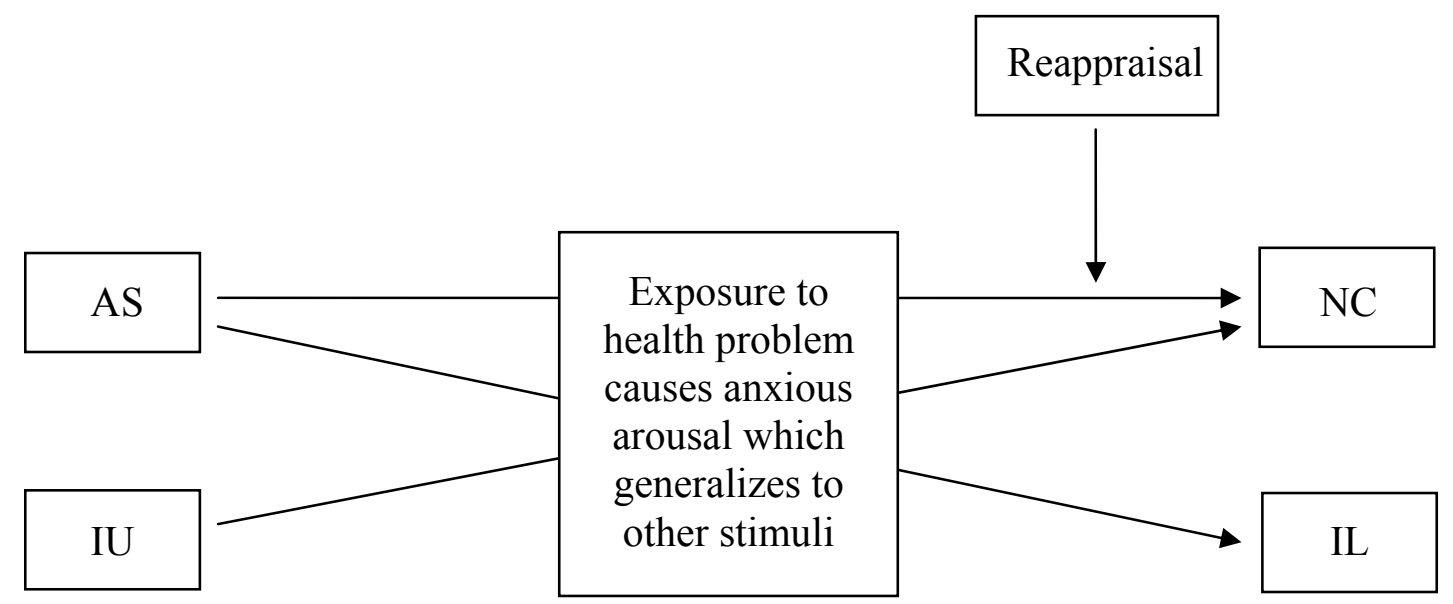

Figure 7. Proposed conceptual model accounting for health anxiety in young adults. For younger adults, intolerance of uncertainty (IU) and anxiety sensitivity (AS) are predisposing characteristics. Then, individuals are exposed to a serious health problem (in self, others, or news), which causes anxiety-related symptoms. Anxious responding may be generalized to other illness-related stimuli. In the presence of these stimuli, young adults consider perceived likelihood (IL) and negative consequences (NC) or costs of an illness. These anxious thought patterns related to negative consequences are affected by reappraisal skills, which is a coping factor. Also part of the conceptual model (not displayed) is the availability of rescue factors, such as cures, though this factor was not examined in the present study. 


\author{
Lindsay Gerolimatos \\ 465 Wilson Ave, Apt 3 \\ Morgantown, WV 26505 \\ Lindsay.Gerolimatos@mail.wvu.edu
}

(516) 680-9099

EDUCATION:

West Virginia University, Morgantown, WV, Fall 2009-present

Master's Thesis: Predictors of Health Anxiety in Older and Younger Adults

Master of Science: Expected August 2011

Expected Graduation Date: May 2014

Expected Degree: Ph.D. in Clinical Psychology

Cornell University, Ithaca, New York, May 2009

Bachelor of Science with Distinction in Human Development

Major: Human Development

Concentration: Social and Personality Development

Minor: Education

Senior Honors Thesis: The self-reference effect and same-age bias in semantic and source memory:

A comparison of elderly and younger adults

\title{
RESEARCH INTERESTS:
}

I am interested in studying anxiety in older adults, in particular health anxiety; the onset and progression of health anxiety; and predictors of health anxiety in late life.

\section{AWARDS:}

- Department of Psychology Student Research Fund (\$750)

- HERF Fellowship, 2009-2010 (\$2,000)

- Human Ecology Alumni Affairs and Development Grant, 2008 (\$400)

- Human Ecology Small Grant, 2008 (\$200)

- Dean's List, Fall 2008

- Dean's List, Spring 2008

- Dean's List, Fall 2007

- Henry Zingale Scholarship, 2005 (\$1,000)

- Howard McSpedon Memorial Scholarship, 2005 (\$5,000)

\section{PROFESSIONAL AFFILIATIONS:}

- American Psychological Association, Division 12, 2011

- Association for Psychological Science, Student Member, 2011

- Gerontological Society of America, Student Member, 2011 


\section{RESEARCH EXPERIENCE:}

At West Virginia University, Morgantown, West Virginia:

Master's Thesis, Predictors of Health Anxiety in Older and Younger Adults, Fall 2009-present Develop research questions and procedure, conducted a review of the literature and wrote a proposal, wrote an IRB, collected preliminary data using SONA, collected thesis data, analyzed results, currently drafting the final defense manuscript.

Research Assistant in Older Adult Anxiety Laboratory, August 2009-present Worked on a variety of studies, including an examination of worry in older adults and its effects on heart rate, development of a social anxiety measure for older adults, and constructing a measure of general anxiety in older adult populations with cognitive impairment. Responsibilities include reviewing the literature, recruiting participants, collecting and entering data, analyzing data, and writing manuscripts.

Research Assistant in Forensic Psychology Laboratory, October 2009-present Read literature related to forensic psychology and read and draft reviews of manuscripts submitted for publication

Research Assistant for APA, Graduate Training Opportunity Study, Fall 2009-Spring 2010 Worked on study examining graduate clinical training programs. Created list of contact information for Directors of Clinical Training for various schools, administered questionnaires to directors, followed-up with phone calls for non-responders.

At Cornell University, Ithaca, New York:

Research Assistant in Social Cognition Laboratory, Spring 2007-May 2009

Required to recruit participants, run participants, develop coding schemes, enter and code data, and assist in data analysis

Became project leader in Spring 2008

Research Assistant in Sociology, Spring 2007

Required to review relevant literature, develop a protocol for the study, run participants, and enter data.

At Mount Sinai School of Medicine, New York, New York:

Intern in the Health Policy Department, Summer 2008

Required to review relevant literature, develop questionnaires and community assessments, present questionnaires at meetings, perform community assessments of East and Central Harlem, and meet with community members for input. 
TEACHING EXPERIENCE:

PSYC 101 Instructor, West Virginia University, Morgantown, WV, Fall 2009 and Spring 2010. Delivered lectures, created study guides, provided extra help outside the classroom, and helped modify exam questions.

PSYC 495 Supervisor, West Virginia University, Morgantown, WV, Fall 2010. Instructed student in conducting research protocols, entering and checking of data, and provided advice on applying to graduate school.

\section{CLINICAL EXPERIENCE:}

QCC Coordinator, Morgantown WV, July 2010-June 2011

Supervisor: William Fremouw, Ph.D.

Location: Quin Curtis Center

Screening new referrals; conducting assessments of ADHD and learning disabilities; organizing workshops.

Vertical Team, Morgantown, WV, Fall 2010-Summer 2011

Supervisor: William Fremouw, Ph.D.

Location: Quin Curtis Center

Cognitive-behavioral treatment for individuals with anger problems; dialectical behavior therapy for individuals with affective instability.

Vertical Team, Morgantown, WV, Fall 2009-Summer 2010

Supervisor: Amy Fiske, Ph.D.

Locations: Family Medicine and Sundale Long Term Care Facility

Cognitive-behavioral treatment for older adults with insomnia; cognitive behavioral treatment for depression in older adults.

\section{WORK EXPERIENCE:}

Sales Associate for Gap, Inc. Westbury, NY, Summer 2007, 2008 \& 2009

Worked mainly as a cashier, but also had to maintain the sales floor, assist customers, and tend to the fitting rooms.

Hostess for Mama Theresa's Pizzeria and Restaurant, Westbury, NY, Summer 2006

Required to manage the dining room and assist the wait staff at busy times; also had to supervise the wait staff when the managers were not available, which included keeping track of bills, ensuring that waiters completed their tasks, and restocking items. 


\section{RELATED EXPERIENCE:}

Volunteer at South Hill Elementary School, Ithaca, New York, 2008

Worked in the art classroom assisting the teacher with her lesson and helping students one-on-one with their artwork

Volunteer at Winthrop University Hospital, Mineola, New York, 2006

Worked in special procedures assisting with patient prep and patient care following procedures and observed procedures such as biopsies

\section{PROFESSIONAL DEVELOPMENT:}

Workshop: Suicide and Malpractice, West Virginia University, Morgantown, WV, November 2, 2010.

Presenter: William Fremouw, Ph.D.

Three-hour workshop describing legal issues pertaining to suicide in psychology practice.

Workshop: Motivational Interviewing, West Virginia University, Morgantown, WV, October 16, 2010

Presenter: Dan McNeil, Ph.D. and Rochelle Cairns, Ph.D.

Six-hour workshop describing skills of motivational interviewing, and practice of these skills during various role-plays and activities.

Workshop: Universal Design in Classrooms, West Virginia University, Morgantown, WV, January 2010-February 2010.

Online course explaining what universal design is, and how to implement it in classroom. Required completion of online modules and pre- and post-exam.

Workshop: Getting Rid of a Grudge: The Science of Forgiveness in Therapy, West Virginia University, Morgantown, WV, November 14, 2009, Presenter: Kevin Larkin, Ph.D.

Three-hour workshop describing empirical research on grudges and forgiveness, therapeutic techniques for helping clients resolve grudges, and presentation of a case-study of grudgeforgiveness therapy.

PROFESSIONAL ACTIVITIES:

Presentation: Quin Curtis Center Orientation, West Virginia University, Morgantown, WV, September 1, 2010.

Presenters: Lindsay Gerolimatos, B.S., and Alison Vargovich, B.A.

Educated first-year clinical psychology students and new faculty on procedures related to the clinic, as well as some legal issues relevant to clinical work. 
Presentation: Quin Curtis Center, West Virginia University, Morgantown, WV, August 18, 2010 Presenters: Lindsay Gerolimatos, B.S. and Alison Vargovich, B.A.

Presented to staff of the Carruth Center on the services provided by the Quin Curtis Center as well as procedure for making referrals to the clinic.

Workshop: Caring for the Caregiver: Recognizing and Treating Mental Health Problems in Family Caregivers. West Virginia University, Morgantown, WV, September 11, 2009.

Presenters: Amy Fiske, Ph.D., Lindsay Gerolimatos, B.S., Reid Kehoe, M.S., Sarra Nazem, M.S., and Elizabeth Price, B.A.

Lectured to first-year Family Medicine residents on empirical research examining caregiver distress and how to detect signs of caregiver burden in patients.

Reviewer for Association for Psychological Science Student Grant Award, Spring 2010-Spring 2011

Reviewer for Association for Psychological Science RiSE Up Award, Spring 2010-Spring 2011 COMMUNITY ACTIVITIES:

Presentation: Sleep and Insomnia in Late Life and Relaxation, Vintage Senior Center, Pittsburgh, PA, November 16, 2010.

Presenters: Caroline Ciliberti, M.S., and Lindsay Gerolimatos, B.S.

Gave a talk to older adults about common sleep difficulties in late life and ways to overcome sleep problems.

Presentation: Relaxation and Stress Management for Older Adults, Elder-Ado Senior Center, Pittsburgh, PA, August 18, 2010.

Presenters: Lindsay Gerolimatos, B.S., and Caroline Ciliberti, M.S.

Led a talk for older adults regarding stressors in late life and taught older adults to use deep

breathing and progressive muscle relaxation to reduce levels of stress.

MANUSCRIPTS:

Edelstein, B.A., Martin, R.R., \& Gerolimatos, L.A. (in progress). Assessment in geriatric settings. In J.R. Graham \& J.A. Naglieri (Eds.), Handbook of Psychology: Assessment Psychology. Hoboken NJ: John Wiley \& Sons, Inc.

Gerolimatos, L.A., \& Edelstein, B.A. (submitted). Contributing factors to health anxiety in younger adults: A preliminary analysis of mediators and moderators. Behavior Therapy. 
Gould, C., Edelstein, B.A., \& Gerolimatos, L.A. (in press). Assessment of Older Adults. In S. Whitbourne \& M. Sliwinski (Eds.), Handbook of Developmental Psychology: Adult Development and Aging. Hoboken, NJ: Wiley-Blackwell.

Gould, C., Smith, M., Ciliberti, C., Gerolimatos, L.A., \& Edelstein, B.A. (in preparation). Measuring social anxiety in late life: A psychometric evaluation of a newly constructed self-report measure of social anxiety.

\section{PAPER PRESENTATIONS:}

Gould, C., Smith, M., Ciliberti, C., Gerolimatos, L.A., \& Edelstein, B.A. (accepted). Measuring social anxiety in late life: A psychometric evaluation of a newly constructed self-report measure of social anxiety. Paper accepted for presentation as part of the symposium: Assessment and Treatment of Older Adult Anxiety. American Psychological Association's $119^{\text {th }}$ Annual Convention.

POSTER PRESENTATIONS:

Gerolimatos, L.A., Nadorff, M., Edelstein, B.A., \& Smith, M. (2010). A Factor Analysis of The Executive Interview (EXIT) Utilizing a Nursing Home Sample. The Gerontological Society of America's 63rd Annual Scientific Meeting.

Doan, S.N., Wang, Q., \& Gerolimatos, L.A. (2009). Self mind-mindedness: Reflecting on one's internal state influences memory. Presented at the $21^{\text {st }}$ Annual Association for Psychological Science Convention. May 23, 2009.

\section{SUBMITTED POSTERS:}

Gerolimatos, L.A., \& Edelstein, B.A. (submitted). Predictors of health anxiety in younger adults: Mediators and moderators. Poster presentation. Association for Behavioral and Cognitive Therapies $45^{\text {th }}$ Annual Convention.

Gerolimatos, L.A., \& Edelstein, B.A. (submitted). Factors contributing to health anxiety in older and younger adults. Poster presentation. Association for Behavioral and Cognitive Therapies $45^{\text {th }}$ Annual Convention.

\section{CONFERENCES ATTENDED:}

- Gerontological Association of America. New Orleans, LA. November 19, 2010-November 23, 2010.

- Anxiety Disorders Association of America. Baltimore, MD. March 5, 2010-March 7, 2010. 
ACTIVITIES:

Alpha Phi Fraternity, 2006-present

Zone Sexual Health Outreach Program sponsored by Gannett Health Services, Cornell University, 2007-2009

Sexual Health Awareness Group (SHAG), Cornell University, 2008-2009

Orientation Leader, Cornell University, Summer 2006

\section{LEADERSHIP:}

Recruitment Advisor, Alpha Phi Fraternity, Beta Iota Chapter, 2010-present

Collegiate Membership Administrator, Alpha Phi Fraternity, 2009-2010

Vice President of Formal Membership Recruitment, Alpha Phi Fraternity, Delta Chapter, 2008-2009

Director of Continuous Open Bidding, Alpha Phi Fraternity, Delta Chapter, 2007-2008

Project Leader of Source Memory Study, Social Cognition Laboratory, Ithaca, New York, 2008

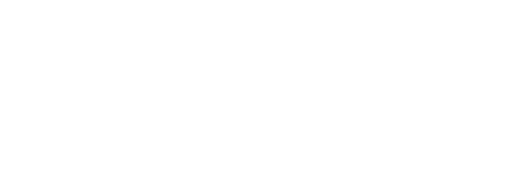

